\title{
Positron emission tomography in animal models of Alzheimer's disease amyloidosis
}

\author{
Ruiqing $\mathrm{Ni}^{1,2^{*}}$ \\ ${ }^{1}$ Institutet for Biomedical Engineering, ETH \& University of Zurich, Zurich, Switzerland \\ ${ }^{2}$ Institute for Regenerative Medicine, University of Zurich, Switzerland \\ * Correspondence: \\ Dr. Ruiqing Ni \\ Email: ni@biomed.ee.ethz.ch;
}

Keywords: Alzheimer's disease; amyloid-beta; animal model; astrocyte; blood-brain barrier; imaging; metabolism; microglia; neuroinflammation, neurotransmitter receptors; positron emission tomography; synaptic density

\begin{abstract}
Animal models of Alzheimer's disease amyloidosis that recapitulate cerebral amyloid-beta pathology have been widely used in preclinical research, and have greatly enabled the mechanistic understanding of Alzheimer's disease and the development of therapeutics. Comprehensive deep phenotyping of the pathophysiological and biochemical features in these animal models are essential. Recent advances in positron emission tomography have allowed the non-invasive visualization of the alterations in the brain of animal models as well as in patients with Alzheimer's disease, These tools have facilitated our understanding of disease mechanisms, and provided longitudinal monitoring of treatment effect in animal models of Alzheimer's disease amyloidosis. In this review, we focus on recent positron emission tomography studies of cerebral amyloid-beta accumulation, hypoglucose metabolism, synaptic and neurotransmitter receptor deficits (cholinergic and glutamatergic system), blood-brain barrier impairment and neuroinflammation (microgliosis and astrocytosis) in animal models of Alzheimer's disease amyloidosis. We further propose the emerging targets and tracers for reflecting the pathophysiological changes, and discuss outstanding challenges in disease animal models and future outlook in on-chip characterization of imaging biomarkers towards clinical translation.
\end{abstract}




\section{Introduction}

Alzheimer's disease (AD) is the most common cause of dementia, afflicting 50 million people worldwide [1]. AD is pathologically featured by amyloid-beta $(\mathrm{A} \beta)$ plaques and neurofibrillary tangles formed by hyperphosphorylated tau, gliosis, neurotransmitter deficits, and neuronal loss leading to cognitive impairment [2,3]. A $\beta$ is produced from through sequential cleavages of amyloid precursor protein (APP) by $\beta$-secretase and $\gamma$-secretase. An imbalance in the production and clearance of A $\beta$ leads to its abnormal cerebral accumulation of $A \beta$ in different forms (oligomers, protofibrils, fibrils and amyloid plaques)[4]. The abnormal accumulation of $\mathrm{A} \beta$ deposits, especially the neurotoxic oligomeric A $\beta$ plays a crucial role in the disease pathogenesis in animal models and in patients with $\mathrm{AD}$ [5-8]. Recent advances in positron emission tomography (PET) using $\left[{ }^{18} \mathrm{~F}\right]$ fluorodeoxyglucose (FDG), tracers for $\mathrm{A} \beta$ pathology and tauopathy, structural magnetic resonance imaging and cerebrospinal fluid biomarkers have provided valuable insights into the time course of pathophysiology of $\mathrm{AD}$ continuum, assisted the early and differential diagnosis, and facilitated the development of therapeutics for $\mathrm{AD}$ [9-13]. A range of molecular imaging tracers for neuroinflammation, synaptic density and neurotransmitter receptor deficits have been developed and provided comprehensive picture of AD [13-16]. Disease animal models recapitulating AD amyloidosis have been developed including transgenic APP/PS1, APP23, APPswe, J20, PS2APP, arcA $\beta, 5 \times$ FAD, $3 \times$ Tg mice, TgF344 and McGill-R-Thy1-APP rats [17-24], $2^{\text {nd }}$ generation App $^{\text {NL-G-F }}$, App $^{\text {hu/hu }}$ knock-in mice $[25,26], 3^{\text {rd }}$ generation mouse models $[27,28]$ as well as non-human primate model [29]. The animal models accumulate cerebral A $\beta$ pathology, develop gliosis, metabolic and synaptic deficits and cognitive impairment assessed by behavior tests, facilitated the understanding of disease mechanisms and the development of treatment strategies. In this review, we focus on the recent development in PET imaging for $A \beta$, alterations in cerebral glucose metabolism, synaptic neurotransmitter receptors, bloodbrain barrier as and neuroinflammation in rodent models of AD amyloidosis. 


\section{Amyloid imaging}

Ex vivo immunohistochemistry in brain tissues from amyloidosis mouse or rat models has revealed that $A \beta$ pathology initiates first in the cortical region, and spreads to the limbic region and finally to the cerebellum [30], in a animal line-dependent manner. More pronounced load of A $\beta$ deposits was observed in $5 \times \mathrm{FAD}$ mice compared to that in APPswe mice [30-32]. In addition to the parenchymal A $\beta$ plaques, cerebral amyloid angiopathy (CAA) is also observed in different amyloidosis animal models especially in the APPDutch mice, Tg-SwDI, APP/London, APP23, $\operatorname{arcA} \beta$ and APPswe mice $[33,34]$. Several A $\beta$ imaging tracers have been developed and applied in animal models of amyloidosis, including benzothiazole derivatives $\left[{ }^{11} \mathrm{C}\right] \mathrm{PiB}, \quad\left[{ }^{18} \mathrm{~F}\right]$ flutemetamol, $\left[{ }^{18} \mathrm{~F}\right]$ florbetaben, $\left[{ }^{18} \mathrm{~F}\right] \mathrm{FIBT}$, $\left[{ }^{18} \mathrm{~F}\right]$ florbetapir, $\left[{ }^{11} \mathrm{C}\right] \mathrm{AZD} 2184,\left[{ }^{18} \mathrm{~F}\right] \mathrm{FC} 119 \mathrm{~S}$ and $\left[{ }^{18} \mathrm{~F}\right]$ flutafuranol, benzofuran derivatives $\left[{ }^{18} \mathrm{~F}\right] \mathrm{FACS}$ and $\left[{ }^{18} \mathrm{~F}\right] \mathrm{FPZBF}-2$, benzoxazole derivaties $\left[{ }^{11} \mathrm{C}\right] \mathrm{BF}-227$ and $\left[{ }^{18} \mathrm{~F}\right] \mathrm{MK} 3328$, benzoselenazole derivative $\left[{ }^{18} \mathrm{~F}\right]$ fluselenamyl. hydroxyquinoline derivative $\left[{ }^{18} \mathrm{~F}\right] \mathrm{CABS} 13$, imidazopyridine derivative $\left[{ }^{18} \mathrm{~F}\right] \mathrm{DRKXH1}$, as well as $\left[{ }^{64} \mathrm{Cu}\right]$ labelled $8 \mathrm{a}^{\prime}-8 \mathrm{~d}$ and HYR-17 [35-52] (Table 1). In addition, singlephoton emission computed tomography (SPECT) tracers imidazopyridine derivative [ ${ }^{125}$ I]DRK092, $\left[{ }^{125} \mathrm{I}\right] \mathrm{CQ}-\mathrm{PBCA}$ nanoparticles, $\left[{ }^{125} \mathrm{I}\right] \mathrm{DRM} 106[53-56]$ and multi-modal imaging tracer $\left[{ }^{18} \mathrm{~F}\right] \mathrm{CDA}-3$ [5759] have been evaluated in amyloidosis rodent models. Higher cortical amyloid PET tracers uptake were observed in various transgenic or knock-in animal models compared to wild-type littermates and validated by the ex vivo immunohistochemical stainings. Longitudinal comparative imaging studies across amyloidosis mouse lines have detected distinct $\mathrm{A} \beta$ spreading patterns in vivo. Snellman et al. showed a greater A $\beta$ tracer dynamic range in the brain of APP23 model compared with that of APPswe and APP/PS1 models by PET imaging using both $\left[{ }^{11} \mathrm{C}\right] \mathrm{PiB}$ and $\left[{ }^{18} \mathrm{~F}\right]$ flutemetamol $[42,60]$. Brendel et al. compared four amyloidosis mouse strains (PS2APP, APPswe/PS1G384A, APP/PS1, APPswe) and found that PS2APP mice demonstrated greater dynamic changes in the longitudinal $\left[{ }^{18} \mathrm{~F}\right]$ florbetaben 
imaging study [61] (Fig. 1d). Moreover, comparative studies of amyloid imaging tracers have been performed in a head-to-head manner in animal models, such as comparing $\left[{ }^{11} \mathrm{C}\right] \mathrm{PiB},\left[{ }^{18} \mathrm{~F}\right]$ florbetaben, and $\left[{ }^{18} \mathrm{~F}\right] \mathrm{FIBT}[40]$, and comparing $\left[{ }^{18} \mathrm{~F}\right]$ florbetaben and $\left[{ }^{18} \mathrm{~F}\right]$ flutemetamol [62]; Similar patterns of tracer detection of cerebral A $\beta$ distribution in the animal models have been reported in general. Sacher et al. showed an asymmetry and hemispheric predominance of A $\beta$ accumulation detected by using $\left[{ }^{18} \mathrm{~F}\right]$ florbetaben accompanied by microglial activation assessed by using $\left[{ }^{18} \mathrm{~F}\right] \mathrm{GE}-180$ in five mouse lines including APP/PS1, PS2APP, APP-SL70, APPswe transgenic mice and App ${ }^{\text {NL-G-F }}$ knock-in mice [63].

As the commonly used amyloid tracers cannot differentiate parenchymal A $\beta$ plaques and CAA [64], efforts have been made to develop CAA specific tracers such as resorufin derivatives $[65],\left[{ }^{3} \mathrm{H}\right] 1,2$ [66], and $\left[{ }^{99 \mathrm{~m}} \mathrm{Tc}\right]$ hydroxamamide complexes [67]. One of the unsolved question in $\mathrm{A} \beta$ imaging is the detection towards small forms of A $\beta$ aggregates. Biechele et al. recently indicated that the non-fibrillar $A \beta$ (positive for 3552 antibody) in addition to the Thiazine red stained fibrillar $A \beta$ significantly impacted the $\left[{ }^{18} \mathrm{~F}\right]$ florbetaben PET signal in App ${ }^{\mathrm{NL}-\mathrm{G}-\mathrm{F}}$ and APP/PS 1 mice from 3-12 month-of-age [68]. In addition to the small chemical dyes, PET using A $\beta$ antibodies conjugated to a transferrin receptor

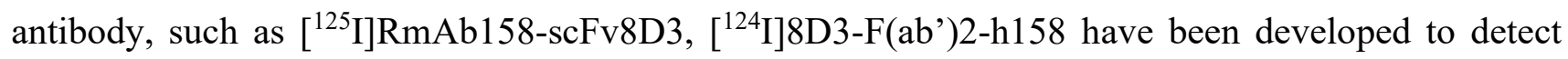
cerebral accumulation of small forms of $\mathrm{A} \beta$. These tracers habor an improved blood-brain barrier permeability and have been demonstrated in several transgenic mouse models of amyloidosis $[53,69,70]$. Meier et al. demonstrated that the uptake of $\left[{ }^{125} \mathrm{I}\right] \mathrm{RmAb} 158-\mathrm{scFv} 8 \mathrm{D} 3$ and $\left[{ }^{124} \mathrm{I}\right] 8 \mathrm{D} 3-\mathrm{F}(\mathrm{ab})$ ')-h158 was significantly higher in the cortical regions of transgenic ArcSwe mice compared with non-transgenic littermates. In addition, the distribution pattern of PET using $\left[{ }^{124} \mathrm{I}\right] 8 \mathrm{D} 3-\mathrm{F}(\mathrm{ab})$ ')-h158 differs from that by PET using $\left[{ }^{11} \mathrm{C}\right] \mathrm{PiB}$ in the brain of tg-ArcSwe mice, indicating preference to different types of $\mathrm{A} \beta$ by these two tracers (Figs. 1a-c)[70]. Given the quantitativeness of in vivo microPET, non-invasive 
imaging using $\left[{ }^{18} \mathrm{~F}\right]$ florbetaben and $\left[{ }^{18} \mathrm{~F}\right]$ florbetapir for $\mathrm{A} \beta$ load have been applied for longitudinal monitoring of the treatment effect in animal models, such as using $\gamma$-secretase modulator, and $\beta$ secretase 1 inhibitor [71-73]. Xu et al. recently demonstrated using $\left[{ }^{11} \mathrm{C}\right] \mathrm{SGSM}-1560$ for in vivo detection of an increased level of $\gamma$-secretase in $5 \times$ FAD compared to wild-type mice [74] (Figs. 2 h-j).

\section{Cerebral glucose metabolism imaging}

Brain glucose dysregulation plays an important role in AD [75]. Post-mortem studies reported higher levels of brain tissue glucose concentration, lower levels of glucose transporter 3, and glycolytic flux in brain from patients with AD compared to controls, associating with the severity of AD pathology [75]. Accumulating evidence also indicates a link between diabetes and AD [76]. $\left[{ }^{18} \mathrm{~F}\right] \mathrm{FDG}$ PET have been routinely used for detecting the reduced cerebral glucose metabolism (CMRglc) in disease specific brain regions in patients with AD, Frontotemporal dementia and Parkinson's disease to improve the diagnostic accuracy $[11,77]$. In lab settings, $\left[{ }^{18} \mathrm{~F}\right] \mathrm{FDG}$ PET have been assessed along with $\mathrm{A} \beta$ imaging in various amyloidosis rodent models such as APPswe mice, $5 \times \mathrm{FAD}, \mathrm{APP} / \mathrm{PS} 1,3 \times \mathrm{Tg}$, Tg4-42, TASTPM mice, and McGill-R-Thy1-APP rats [47,78-84] (Table 2). Most of the studies in rodent amyloidosis models reported a global reduction in CMRglc, although few exception of increased CMRglc (associating with gliosis) was also reported [85]. Several studies have reported the longitudinal temporal and spatial association between the reginal patterns of reduced $\left[{ }^{18} \mathrm{~F}\right] \mathrm{FDG}$ uptake and $\mathrm{A} \beta$ deposition using $\left[{ }^{11} \mathrm{C}\right] \mathrm{PiB}$ or $\left[{ }^{18} \mathrm{~F}\right]$ florbetaben $[86,87]$, and with microglial activation such as using $\left[{ }^{18} \mathrm{~F}\right] \mathrm{GE}-180$ [87] (Figs. 1e-h), and $\left[{ }^{18} \mathrm{~F}\right] \mathrm{DPA}-714$ in animal models [88]. Tsukada et al. reported reduced $\left[{ }^{18} \mathrm{~F}\right] \mathrm{FDG}$ measures of CMRglc, increased $\left[{ }^{11} \mathrm{C}\right] \mathrm{PiB}$ measures of $\mathrm{A} \beta$ deposition, increased $\left[{ }^{11} \mathrm{C}\right] \mathrm{DPA}-$ 713 for microglia activation, and reduced $\left[{ }^{18} \mathrm{~F}\right] \mathrm{BCPP}-\mathrm{EF}$ for mitochondrial complex 1 in brain of aged monkeys [89]. However $\left[{ }^{18} \mathrm{~F}\right] \mathrm{FDG}$ uptake is known to be highly sensitive to the experimental conditions such as anesthesia, and handling, as well as genotype, age and gender of the animal models [90]. 


\section{Synaptic and neurotransmitter receptor deficits}

\subsection{Synaptic vesicle glycoprotein $2 \mathrm{~A}$}

Synapse loss is reported in post-mortem frontal cortex of patients with $\mathrm{AD}$, correlating with cognitive severity [91]. Imaging biomarkers reflecting the synapse damage or loss are thus highly desired [92]. Amyloidosis animal models show cortical, hippocampal atrophy and enlargement of ventricle assessed by using structural magnetic resonance imaging, although to a less extent compared to that in tauopathy animal models [93]. Synaptic vesicle glycoprotein 2A (SV2A) is located at the synapses across the entire brain and is the binding site for the antiepileptic drug levetiracetam [94]. Higher loads of cerebral A $\beta$ deposits have been reported in the brain of SV2A knock out mice compared to control littermates [95]. Several SV2A PET imaging tracers have been developed including $\left[{ }^{11} \mathrm{C}\right] \mathrm{UCB}-\mathrm{J},\left[{ }^{18} \mathrm{~F}\right] \mathrm{UCB}-\mathrm{H}[96]$, $\left[{ }^{18} \mathrm{~F}\right]$ SynVesT-1 [97], $\left[{ }^{18} \mathrm{~F}\right] \mathrm{SDM}-8$ [98] and $\left[{ }^{18} \mathrm{~F}\right] \mathrm{MNI}-1126$ [99] (Table 2). A reduction of approximately $40 \%$ of SV2A signal by PET using $\left[{ }^{11} \mathrm{C}\right] \mathrm{UCB}-\mathrm{J}$ was observed in the hippocampus in patients with AD compared with cognitively normal control cases $[100,101]$. PET measures of A $\beta$ deposition associated with regional synaptic density measured by $\left[{ }^{11} \mathrm{C}\right] \mathrm{UCB}-\mathrm{J}$ in patients with early AD $[100,102]$. Few studies have reported on SV2A imaging in AD animal models. Bertoglio et al. demonstrated that $\left[{ }^{11} \mathrm{C}\right] \mathrm{UCB}-\mathrm{J}$ bound specifically to SV2A in mouse brain, and that the radioligand binding can be quantified by kinetic modeling using an image-derived input function [103]. Toyonaga showed that in vivo $\left[{ }^{11} \mathrm{C}\right] \mathrm{UCB}-$ $\mathrm{J}$ detected reduced levels of SV2A in APP/PS1 mice, and the treatment effects of tyrosine kinase Fyn inhibitor Saracatinib in mitigating the $\left[{ }^{11} \mathrm{C}\right] \mathrm{UCB}-\mathrm{J}$ reduction [104]. Xiong et al. recently compared the $\left[{ }^{11} \mathrm{C}\right] \mathrm{UCB}-\mathrm{J}$ binding in tg-ArcSwe and wild-type mice [105], and did not observe clear difference between the two groups. $\left[{ }^{18} \mathrm{~F}\right] \mathrm{SynVesT}-1,\left[{ }^{18} \mathrm{~F}\right]$ analog of $\left[{ }^{11} \mathrm{C}\right] \mathrm{UCB}-\mathrm{J}$, has demonstrated favourable $i n$ vivo brain uptake in non-human primate [106]. Sadasivam et al. showed a lower $\left[{ }^{18} \mathrm{~F}\right] \mathrm{SynVesT}-1$ standard uptake value (SUV) across the whole brain of APP/PS1 mice compared to non-transgenic 
mice [107]. The results from a static (30-60 min post-injection) $\left[{ }^{18} \mathrm{~F}\right] \mathrm{SynVesT}-1 \mathrm{PET}$ scan was found comparable to kinetic modeling results [107].

\subsection{Glutamate receptors}

The glutamate receptors are classified into the $N$-methyl-D-aspartate receptor (NMDAR), $\alpha$-amino-3hydroxy-5-methyl-4-isoxazolepropionate (AMPA)-kainate receptor, and metabotropic glutamate receptors (mGluRs). The glutamate receptors mediate excitatory neurotransmission, involve in multiple second messenger systems and are essential in learning and memory $[108,109]$. Glutamate excitotoxicity, and disruption of the glutamate receptor mediated normal signaling are implicated in $\mathrm{AD}[110,111]$. A $\beta$ reduces glutamatergic transmission and inhibits synaptic plasticity [112,113]. Direct interaction between A $\beta$ oligomers and glutamate receptors including NMDAR [114], mGluR subunit mGluR5 [115], AMPA receptor subunit GluA3 [116] and GluA1 [117] have been demonstrated, leading to impaired synaptic plasticity in the animal models [118]. Chronic pharmacological inhibition of mGluR5 has been shown to prevent the cognitive impairment and reduce pathological development in APP/PS1 mice [119]. Thus glutamate receptors have been important target for AD therapeutics. Several imaging tracers for glutamate receptors have been developed including $\left[{ }^{11} \mathrm{C}\right] \mathrm{K}-2$ [120] and $\left[{ }^{11} \mathrm{C}\right] \mathrm{HMS} 011$ [121] for AMPA receptor, $\left[{ }^{18} \mathrm{~F}\right] \mathrm{GE}-179$ [122] and $\left[{ }^{18} \mathrm{~F}\right] \mathrm{PK}-209$ for NMDAR [123], $\left[{ }^{11} \mathrm{C}\right] \mathrm{Me}-\mathrm{NB} 1$ [124] for NMDAR GluN1/GluN2B subunits [125], as well as $\left[{ }^{18} \mathrm{~F}\right] \mathrm{FPEB},\left[{ }^{11} \mathrm{C}\right] \mathrm{ABP} 688$ and $\left[{ }^{18} \mathrm{~F}\right]$ PSS232 for mGluR5 [126-128]. In patients with AD, PET using [ $\left.{ }^{18} \mathrm{~F}\right] \mathrm{FPEB}$ [129] and $\left[{ }^{11} \mathrm{C}\right] \mathrm{ABP} 688[130]$ revealed consistant reductions in regional mGluR5 binding in the hippocampus and amygdala compared to non-demented controls. Sofar only mGluR5 imaging have been reported in amyloidosis animal models and showed conflicting results probably due to different animal models utilized (Table 2). Lee et al. demonstrated an age-dependent $35 \%$ decrease in the level of $\left[{ }^{18} \mathrm{~F}\right] \mathrm{FPEB}$ measures of mGluR5 in the cortical and subcortical brain areas in $5 \times$ FAD mice at 9 month compared 
to 3 month-of-age, validated by ex vivo assessment of mGluR5 protein expression level [131]. However Varlow et al. showed that $\left[{ }^{18} \mathrm{~F}\right] \mathrm{FPEB}$ uptake increased in the brain of 10 month-old APP/PS1 mice compared with controls [132]. Fang et al. reported similar levels of $\left[{ }^{18} \mathrm{~F}\right] \mathrm{FPEB}$ uptake in the brain of Tg-ArcSwe mice compared to control mice at different ages [133]. However immunoblotting results indicated that the level of mGluR5 in Tg-ArcSwe mouse brain lysate was higher compared to control mice, at 12 month-of-age, not at 8 and 16 month-of age [133]. Further studies are needed to elucidate the dynamic alteration in glutamate receptors in $\mathrm{AD}$ animal models.

\subsection{Cholinergic system}

The cholinergic system is essential for learning, memory formation, attention, for regulating inflammation [134].. The cholinergic system includes nicotinic acetylcholine receptors (nAChR), muscarinic acetylcholine receptors (mAChR), acetylcholinesterase (AChE). and butyrylcholinesterase (BChE). $\alpha 7 \mathrm{nAChR}$ and $\alpha 4 \beta 2 \mathrm{nAChR}$ are the most abundant nAChR subtypes in the brain. The cholinergic system is impaired early in $\mathrm{AD}$ associating with the cognitive, behavioral and global functioning decline [134-136]. Reduced basal forebrain cholinergic neurons, increased levels of $\alpha 7$ nAChR [137,138] and reduced levels of M1 mAChR [139] were reported in the cortical regions of postmortem brain from AD patients compared to control. Interaction between $\alpha 7$ as well as $\alpha 4 \beta 2 \mathrm{nAChR}$ and different forms of $A \beta$ aggregates have also been reported [140-143]. Several recent PET tracers, including $\left[{ }^{11} \mathrm{C}\right] \mathrm{NS} 14492[144],\left[{ }^{11} \mathrm{C}\right](\mathrm{R}) \mathrm{MeQAA}[145]$, and $\left[{ }^{18} \mathrm{~F}\right] \mathrm{ASEM}$ for $\alpha 7 \mathrm{nAChR}[146],\left[{ }^{11} \mathrm{C}\right](+) 3-$ MPB [147] and [ ${ }^{18} \mathrm{~F}$ fluorobenzyl-dexetimide [148] for mAChR, $\left[{ }^{11} \mathrm{C}\right] \mathrm{LSN} 3172176$ [149] for M1 mAChR, and $\left[{ }^{11} \mathrm{C}\right] \mathrm{MK}-6884$ for M4 mAChR [150] have been developed (Table 2). PET using $\left[{ }^{11} \mathrm{C}\right]$ nicotine imaging showed that the cortical nAChR binding correlated with the cognitive function of attention in patients with mild $\mathrm{AD}$ [151]. Few in vivo PET studies for cholinergic system have been performed in AD models. Nishiyama et al. demonstrated higher $\left[{ }^{11} \mathrm{C}\right](\mathrm{R})-\mathrm{MeQAA}$ brain uptake in the thalamus, hippocampus, striatum, and cortical regions, along with increased $\left[{ }^{11} \mathrm{C}\right] \mathrm{PiB}$ detection of $\mathrm{A} \beta$ 
load and impaired $\left[{ }^{18} \mathrm{~F}\right] \mathrm{BCPP}-\mathrm{EF}$ binding to mitochondrial complex 1 in brain of aged monkey [145]. Chaney et al. demonstrated a lower levels of $\left[{ }^{18} \mathrm{~F}\right] \mathrm{ASEM}$ in TgF334 rats compared to wild-type at 18 month-of-age [152]. Rejc et al. recently reported increased levels of BChE along with $\mathrm{A} \beta$ accumulation using $\left[{ }^{11} \mathrm{C}\right] 4$ and $\left[{ }^{18} \mathrm{~F}\right]$ florbetaben respectively in brain of $5 \times \mathrm{FAD}$ mice at $4-12$ months-of-age compared to wild-type mice [153] (Figs. 3c-e). In comparison, comparable levels of AChE were observed in APP23 compared to wild-type mice at 10-13 months-of-age assessed by PET using $\left[{ }^{11} \mathrm{C}\right] \mathrm{MP} 4 \mathrm{~A}[154]$.

\section{Blood-brain barrier}

Blood-brain barrier $(\mathrm{BBB})$ is impaired at an early disease stage in $\mathrm{AD}[155,156]$. Whether the $\mathrm{BBB}$ dysfunction is secondary to $A \beta$ pathology or a causal factor has not been fully elucidated. In amyloidosis animal models of $\mathrm{AD}, \mathrm{BBB}$ disruption is observed in mouse models such as arcA $\beta$, APP/PS1, but not prevalent in certain mouse line such as PS2APP line [157,158]. Several receptors presented in the BBB have been explored as PET imaging targets, such as adenosine triphosphatebinding cassette $(\mathrm{ABC})$ transporter $\mathrm{ABCC} 1, \mathrm{ABCG} 2, \mathrm{ABCB} 1$ (P-glycoprotein, P-gp), and receptor for advanced glycation endproducts (RAGE). P-gp plays an important role in the clearance and efflux of $\mathrm{A} \beta$ from the brain into the blood across the brain endothelial luminal membrane [159]. The levels of Pgp expression and activity were found decreased in the brains of $\mathrm{AD}$ patients compared to that in control cases, as well as in APP mouse model compared to wild-type mice [160]. Several P-gp tracers such as (R)-O- $\left[{ }^{18} \mathrm{~F}\right]$ fluoroethylnorverapamil, (R)-N- $\left[{ }^{18} \mathrm{~F}\right]$ fluoroethylverapamil, (R)- $\left[{ }^{11} \mathrm{C}\right]$ verapamil, $\left[{ }^{11} \mathrm{C}\right]$ tariquidar, $\left[{ }^{11} \mathrm{C}\right]$ metoclopramide, and $\left[{ }^{18} \mathrm{~F}\right] \mathrm{MC} 225$ have been developed [161-168] (Table 2). Zoufal et al. demonstrated an age-dependent reduction in the cerebral P-gp function in APP/PS1 mice compared to wild-type mice assessed by PET using $(R)-\left[{ }^{11} \mathrm{C}\right]$ verapamil [161] (Figs. 2d-g) and by using $\left[{ }^{11} \mathrm{C}\right]$ metoclopramide [162]. However $(R)-\left[{ }^{11} \mathrm{C}\right]$ verapamil showed suboptimal brain uptake, and further 
improvement and evaluation of P-gp function using novel tracers with improved properties are needed. In addition, PET using 6-bromo-7-[ $\left[{ }^{11} \mathrm{C}\right]$ methylpurine $\left(\left[{ }^{11} \mathrm{C}\right] \mathrm{BMP}\right)$ showed an increased level of $\mathrm{ABCC} 1$ along with $\left[{ }^{11} \mathrm{C}\right] \mathrm{PiB}$ detection of increased level of $\mathrm{A} \beta$ pathology in the brain of APP/PS1 mice compared to wild-type mice [165]. The increase in the ABCC1 level has been assumed relating to upregulation of its expression in astrocytes as a protective mechanism. Imaging of ABCG2 by PET using $\left[{ }^{11} \mathrm{C}\right]$ erlotinib have been reported in APP/PS1 mice: no alteration in the level of ABCG2 compared to wild-type mice was observed [166].

Receptor for advanced glycation end products (RAGE) is a BBB transporter, and a binding site for advanced glycation end products, and mediates $\mathrm{A} \beta$ transportation across the $\mathrm{BBB}$ into the brain $[169,170]$. The expression level of RAGE was found increased in post-mortem AD brains compared to that in control cases [169]. RAGE tracers such as $\left[{ }^{11} \mathrm{C}\right] \mathrm{FPS}-\mathrm{ZM} 1$ [171], [ $\left.{ }^{18} \mathrm{~F}\right] \mathrm{RAGER}$ [172], $\left[{ }^{18} \mathrm{~F}\right]$ InRAGER [173], and $\left[{ }^{64} \mathrm{Cu}\right] \mathrm{Rho-G4-CML}$ nanoparticle (multimodal) have been developed [174]. The only imaging study conducted in AD animal model by Luzi et al. showed that $\left[{ }^{11} \mathrm{C}\right] \mathrm{FPS}-\mathrm{ZM} 1$ uptake in the brain of APPswe was similar compared to that of wild-type mice [175]. Further development and studies are needed to evaluate RAGE imaging tracers in AD animal models and in patients with AD.

\section{Neuroinflammation imaging}

Several recent articles have provided thorough reviews on neuroinflammation PET imaging in AD patients and AD animal models [16,176-180]. Thus here we discuss briefly the recent development in neuroinflammation imaging in AD amyloidosis animal models. Neuroinflammation plays an important role in the pathogenesis of AD and appears early in the disease development [181-183]. Microglia are the resident macrophages in the central nervous system, engulf $A \beta$ plaques and are important for maintaining the brain homeostasis $[183,184]$. Recent single cell sequencing and transcriptomics have 
demonstrated a transcriptionally-distinct and neurodegeneration-specific profile of microglia termed disease-associated-microglia (DAM) [185-187]. The $18 \mathrm{kDa}$ translocator protein (TSPO) that located on the outer mitochrondria membrane of microglia has been the most investigated target for microgliosis PET imaging. Three generations of TSPO tracers have been developed with improved properties, from the $1^{\text {st }}$ generation $(\mathrm{R})-\left[{ }^{11} \mathrm{C}\right] \mathrm{PK} 11195[188] ; 2^{\text {nd }}$ generation $\left[{ }^{11} \mathrm{C}\right] \mathrm{PBR} 28$ [189], $\left[{ }^{125} \mathrm{I}\right] \mathrm{CLINDE}[54]$, $\left[{ }^{18} \mathrm{~F}\right]$ FEDAA1106 [190], $\left[{ }^{18} \mathrm{~F}\right] \mathrm{DPA}-714[88]$ to the $3^{\text {rd }}$ generation $\left[{ }^{18} \mathrm{~F}\right] \mathrm{GE}-180$ [87] (Figs. 1e-h) and $\left[{ }^{11} \mathrm{C}\right] \mathrm{ER} 176$ [191]. PET using various $18 \mathrm{kDa}$ translocator protein (TSPO) tracers have demonstrated an early microgliosis preceding the $A \beta$ deposition in several animal models of amyloidosis including APP23, hAPP-J20, APPSL70, App ${ }^{\text {NL-G-F }}$ and PS2APP mice [184,192-197]. Due to the diverse cellular location of TSPO expression on astrocytes and endothelial cells in addition to that on microglia, tracers specific for microglial expression and of disease-associated profile are of high interest [198-200]. Emerging targets and tracers include $\left[{ }^{11} \mathrm{C}\right] \mathrm{SW} 125 \mathrm{M} 139$ for purinergic P2X7 receptor $[201,202],\left[{ }^{124} \mathrm{I}\right]$ mAb1729-scFv8D3CL for triggering receptors expressed on myeloid cells (TREM) 2, [ ${ }^{11}$ C]AZD1283 for purinergic P2Y12 receptor [203], $\left[{ }^{11} \mathrm{C}\right] \mathrm{CPPC}[204]$ and $\left[{ }^{11} \mathrm{C}\right] \mathrm{GW} 2580$ [205] for colony stimulating factor 1 receptor, $\left[{ }^{11} \mathrm{C}\right] \mathrm{KTP}-\mathrm{Me}$ for cyclooxygenase 1 [206] etc have been developed and been evaluated in AD animal models. Meier et al. showed a higher expression level of TREM2 in brain from ArcSwe mice compared to wild-type mice at $24 \mathrm{~h}, 48 \mathrm{~h}$, and $72 \mathrm{~h}$ post-injection by autoradiography using $\left[{ }^{124} \mathrm{I}\right]$ mAb1729-scFv8D3CL [207] (Figs. 3f-I).

\section{Discussion}

In addition to the aforementioned targets, many emerging targets show potential as indicators for pathological alterations in $\mathrm{AD}$, and are yet to be further investigated in amyloidosis animal models, such as 1) metal dysregulation and copper trafficking e.g. using $\left[{ }^{64} \mathrm{Cu}\right] \mathrm{GTSM}$ [208]; 2) reactive oxygen species [209] and $\mathrm{pH}$ alterations [210]; 3) microtubule using $\left[{ }^{11} \mathrm{C}\right] \mathrm{MPC}-6827,\left[{ }^{11} \mathrm{C}\right] \mathrm{HD}-800,\left[{ }^{11} \mathrm{C}\right] \mathrm{WX}-$ 132-18B[211-213]; 4) sigma 1 receptor using $\left[{ }^{11} \mathrm{C}\right] \mathrm{HCC} 0929,\left[{ }^{18} \mathrm{~F}\right] \mathrm{FTC}-146,\left[{ }^{18} \mathrm{~F}\right] \mathrm{IAM} 6067$ and 
$\left[{ }^{11} \mathrm{C}\right] \mathrm{SA} 4503$ [214-216]: 5) mitochondria imaging using [ $\left.{ }^{18} \mathrm{~F}\right] \mathrm{BCPP}-\mathrm{EF}$ [217]; and 6) Glycogen Synthase Kinase-3 imaging using $\left[{ }^{11} \mathrm{C}\right] 2,\left[{ }^{11} \mathrm{C}\right] \mathrm{OCM}-44,\left[{ }^{3} \mathrm{H}\right] \mathrm{PF}-367[218,219]$.

Astrocytes are essential for maintaining the homeostasis, synaptic plasticity and inflammatory response in the central nervous system [220]. Astrocytes play key roles in the onset and progression of AD. Reactive astrocytes show disease-associated profiles and exert dynamic functions (neuroprotection and neurotoxicity) in AD [221-225]. Few studies have been reported on PET imaging of astrocytosis in AD animal models. PET using irreversible mono-amine oxidase B (MAO-B) inhibitors $\left[{ }^{11} \mathrm{C}\right]$ deuterium-Ldeprenyl (DED) showed an early astrocytosis preceding the $\mathrm{A} \beta$ accumulation assessed by using $\left[{ }^{11} \mathrm{C}\right] \mathrm{AZD} 2184$ in the brain of APPswe at 6 months-of-age compared to wild-type mice (Figs. 3a, b). Similar finding of an early increase in $\left[{ }^{11} \mathrm{C}\right] \mathrm{DED}$ binding was reported in Tg-ArcSwe mice compared to wild-type littermates [226]. Several novel MAO-B tracers have been developed including $\left[{ }^{11} \mathrm{C}\right] \mathrm{SMBT}-1$ [227] based on $(S)-\left[{ }^{18} \mathrm{~F}\right] \mathrm{THK} 5117$ structure [228] and $\left[{ }^{18} \mathrm{~F}\right] 6$ [229]. In addition, novel astrocytic tracer $\left[{ }^{11} \mathrm{C}\right] \mathrm{BU} 99008$, which targets imidazoline-2 binding sites (I2BS), has showed specific and high-affinity binding property in post-mortem characterization [230]. in vivo PET in patients with $\mathrm{AD}[231,232]$.

In vivo longitudinal imaging in animal models of $\mathrm{AD}$ amyloidosis has provided valuable insights on the spatiotemporal links between different pathophysiology. The challenges in bridging the translational gaps of PET imaging in rodent models and in patients with AD may include:

- Animal model: Different rodent models of AD demonstrated divergent time courses and patterns of pathophysiological development $[32,233,234]$. Thus rational selection of optimal animal model and age for investigation are thus critical in PET imaging studies in tracer evaluation [235]. In addition, species difference in cell types, protein expression level, available binding sites, post-translational 
modification of the target added to the complexity [236]. For example, the A $\beta$ deposits formed in the APP mouse models and in aged primates are structurally different from that in the brain from patients with AD [237]. Thus, models that better recapitulate the human AD pathology will greatly boost the $\mathrm{AD}$ research, such as the recent $\mathrm{A} \beta-\mathrm{KI}$ mouse model of late-onset $\mathrm{AD}[28], 3^{\text {rd }}$ generation mouse model [27]; Moreover, databases of comprehensive deep phenotyping in disease animal models such as "MODEL-AD" by the Alzheimer consortium think tank [238,239] (www.model-ad.org/) are instrumental in facilitating the translational research. Systems biology approaches including single cell sequencing, transcriptomics, biochemical characterization, and behavioural assessments along with in vivo imaging data will provide accurate interpretation of the readouts [240-243].

\section{Conclusions}

We provide an overview of PET imaging in animal models of AD amyloidosis, highlighting recent development in visualizing $\mathrm{A} \beta$, cerebral glucose metabolism, synaptic and neurotransmitter receptor deficits, BBB impairment and neuroinflammation, and proposed outstanding challenges for future development to increase the translational power of preclinical PET in AD.

\section{Conflict of Interest}

The authors declare that the research was conducted in the absence of any commercial or financial relationships that could be construed as a potential conflict of interest.

\section{Author Contributions}

$\mathrm{RN}$ wrote the manuscript and approved the submission.

\section{Funding}


RN received funding from Helmut Horten Stiftung, Vontobel Stiftung

\section{References}

1. Bhatt, J.; Comas Herrera, A.; Amico, F.; Farina, N.; Wong, J.; Orange, J.B.; Gaber, S.; Knapp, M.; Salcher-Konrad, M.; Stevens, M.; et al. The World Alzheimer Report 2019: Attitudes to dementia; 2019.

2. Scheltens, P.; De Strooper, B.; Kivipelto, M.; Holstege, H.; Chételat, G.; Teunissen, C.E.; Cummings, J.; van der Flier, W.M. Alzheimer's disease. Lancet 2021, 397, 1577-1590, doi:10.1016/s0140-6736(20)32205-4.

3. Knopman, D.S.; Amieva, H.; Petersen, R.C.; Chételat, G.; Holtzman, D.M.; Hyman, B.T.; Nixon, R.A.; Jones, D.T. Alzheimer disease. Nat Rev Dis Primers 2021, 7, 33, doi:10.1038/s41572-021-00269-y.

4. Selkoe, D.J.; Hardy, J. The amyloid hypothesis of Alzheimer's disease at 25 years. EMBO Mol Med 2016, doi:10.15252/emmm.201606210.

5. Lesné, S.; Koh, M.T.; Kotilinek, L.; Kayed, R.; Glabe, C.G.; Yang, A.; Gallagher, M.; Ashe, K.H. A specific amyloid- $\beta$ protein assembly in the brain impairs memory. Nature 2006, 440, 352-357, doi:10.1038/nature04533.

6. Haass, C.; Selkoe, D.J. Soluble protein oligomers in neurodegeneration: lessons from the Alzheimer's amyloid beta-peptide. Nat Rev Mol Cell Biol 2007, 8, 101-112, doi:10.1038/nrm2101.

7. Lambert, M.P.; Velasco, P.T.; Chang, L.; Viola, K.L.; Fernandez, S.; Lacor, P.N.; Khuon, D.; Gong, Y.; Bigio, E.H.; Shaw, P.; et al. Monoclonal antibodies that target pathological assemblies of A $\beta$. J. Neurochem. 2007, 100, 23-35, doi:10.1111/j.1471-4159.2006.04157.x.

8. Shankar, G.M.; Li, S.; Mehta, T.H.; Garcia-Munoz, A.; Shepardson, N.E.; Smith, I.; Brett, F.M.; Farrell, M.A.; Rowan, M.J.; Lemere, C.A.; et al. Amyloid- $\beta$ protein dimers isolated directly from Alzheimer's brains impair synaptic plasticity and memory. Nat Med 2008, 14, 837-842, doi:10.1038/nm1782.

9. Jack, C.R., Jr.; Bennett, D.A.; Blennow, K.; Carrillo, M.C.; Dunn, B.; Haeberlein, S.B.; Holtzman, D.M.; Jagust, W.; Jessen, F.; Karlawish, J.; et al. NIA-AA Research Framework: Toward a biological definition of Alzheimer's disease. Alzheimers Dement 2018, 14, 535-562, doi:10.1016/j.jalz.2018.02.018.

10. Cotta Ramusino, M.; Perini, G.; Altomare, D.; Barbarino, P.; Weidner, W.; Salvini Porro, G.; Barkhof, F.; Rabinovici, G.D.; van der Flier, W.M.; Frisoni, G.B.; et al. Outcomes of clinical utility in amyloid-PET studies: state of art and future perspectives. European Journal of Nuclear Medicine and Molecular Imaging 2021, 48, 2157-2168, doi:10.1007/s00259-02005187-x.

11. Chételat, G.; Arbizu, J.; Barthel, H.; Garibotto, V.; Law, I.; Morbelli, S.; van de Giessen, E.; Agosta, F.; Barkhof, F.; Brooks, D.J.; et al. Amyloid-PET and (18)F-FDG-PET in the diagnostic investigation of Alzheimer's disease and other dementias. Lancet Neurol 2020, 19, 951-962, doi:10.1016/s1474-4422(20)30314-8.

12. Dubois, B.; Villain, N.; Frisoni, G.B.; Rabinovici, G.D.; Sabbagh, M.; Cappa, S.; Bejanin, A.; Bombois, S.; Epelbaum, S.; Teichmann, M.; et al. Clinical diagnosis of Alzheimer's disease: 
recommendations of the International Working Group. Lancet Neurol 2021, 20, 484-496, doi:10.1016/s1474-4422(21)00066-1.

13. Perani, D.; Iaccarino, L.; Lammertsma, A.A.; Windhorst, A.D.; Edison, P.; Boellaard, R.; Hansson, O.; Nordberg, A.; Jacobs, A.H. A new perspective for advanced positron emission tomography-based molecular imaging in neurodegenerative proteinopathies. Alzheimers Dement 2019, 15, 1081-1103, doi:10.1016/j.jalz.2019.02.004.

14. Thomsen, M.B.; Jacobsen, J.; Lillethorup, T.P.; Schacht, A.C.; Simonsen, M.; RomeroRamos, M.; Brooks, D.J.; Landau, A.M. In vivo imaging of synaptic SV2A protein density in healthy and striatal-lesioned rats with [11C]UCB-J PET. J Cereb Blood Flow Metab 2021, 41, 819-830, doi:10.1177/0271678x20931140.

15. Parbo, P.; Ismail, R.; Hansen, K.V.; Amidi, A.; Mårup, F.H.; Gottrup, H.; Brændgaard, H.; Eriksson, B.O.; Eskildsen, S.F.; Lund, T.E.; et al. Brain inflammation accompanies amyloid in the majority of mild cognitive impairment cases due to Alzheimer's disease. Brain 2017, 140, 2002-2011, doi:10.1093/brain/awx120.

16. Bellaver, B.; Ferrari-Souza, J.P.; Uglione da Ros, L.; Carter, S.F.; Rodriguez-Vieitez, E.; Nordberg, A.; Pellerin, L.; Rosa-Neto, P.; Leffa, D.T.; Zimmer, E.R. Astrocyte Biomarkers in Alzheimer Disease: A Systematic Review and Meta-analysis. Neurology 2021, doi:10.1212/wnl.0000000000012109.

17. Radde, R.; Bolmont, T.; Kaeser, S.A.; Coomaraswamy, J.; Lindau, D.; Stoltze, L.; Calhoun, M.E.; Jaggi, F.; Wolburg, H.; Gengler, S.; et al. Abeta42-driven cerebral amyloidosis in transgenic mice reveals early and robust pathology. EMBO Rep 2006, 7, 940-946, doi:10.1038/sj.embor.7400784.

18. Hsiao, K.; Chapman, P.; Nilsen, S.; Eckman, C.; Harigaya, Y.; Younkin, S.; Yang, F.; Cole, G. Correlative memory deficits, Abeta elevation, and amyloid plaques in transgenic mice. Science 1996, 274, 99-102, doi:10.1126/science.274.5284.99.

19. Mucke, L.; Masliah, E.; Yu, G.Q.; Mallory, M.; Rockenstein, E.M.; Tatsuno, G.; Hu, K.; Kholodenko, D.; Johnson-Wood, K.; McConlogue, L. High-level neuronal expression of abeta 1-42 in wild-type human amyloid protein precursor transgenic mice: synaptotoxicity without plaque formation. J Neurosci 2000, 20, 4050-4058, doi:10.1523/jneurosci.20-1104050.2000 .

20. Richards, J.G.; Higgins, G.A.; Ouagazzal, A.M.; Ozmen, L.; Kew, J.N.; Bohrmann, B.; Malherbe, P.; Brockhaus, M.; Loetscher, H.; Czech, C.; et al. PS2APP transgenic mice, coexpressing hPS2mut and hAPPswe, show age-related cognitive deficits associated with discrete brain amyloid deposition and inflammation. J Neurosci 2003, 23, 8989-9003, doi:10.1523/jneurosci.23-26-08989.2003.

21. Sturchler-Pierrat, C.; Abramowski, D.; Duke, M.; Wiederhold, K.H.; Mistl, C.; Rothacher, S.; Ledermann, B.; Bürki, K.; Frey, P.; Paganetti, P.A.; et al. Two amyloid precursor protein transgenic mouse models with Alzheimer disease-like pathology. Proc Natl Acad Sci US A 1997, 94, 13287-13292, doi:10.1073/pnas.94.24.13287.

22. Oakley, H.; Cole, S.L.; Logan, S.; Maus, E.; Shao, P.; Craft, J.; Guillozet-Bongaarts, A.; Ohno, M.; Disterhoft, J.; Van Eldik, L.; et al. Intraneuronal beta-amyloid aggregates, neurodegeneration, and neuron loss in transgenic mice with five familial Alzheimer's disease mutations: potential factors in amyloid plaque formation. J Neurosci 2006, 26, 10129-10140, doi:10.1523/jneurosci.1202-06.2006. 
23. Oddo, S.; Caccamo, A.; Shepherd, J.D.; Murphy, M.P.; Golde, T.E.; Kayed, R.; Metherate, R.; Mattson, M.P.; Akbari, Y.; LaFerla, F.M. Triple-transgenic model of Alzheimer's disease with plaques and tangles: intracellular Abeta and synaptic dysfunction. Neuron 2003, 39, 409421, doi:10.1016/s0896-6273(03)00434-3.

24. Ni, R.; Dean-Ben, X.L.; Kirschenbaum, D.; Rudin, M.; Chen, Z.; Crimi, A.; Voigt, F.F.; Nilsson, K.P.R.; Helmchen, F.; Nitsch, R. Whole brain optoacoustic tomography reveals strain-specific regional beta-amyloid densities in Alzheimer's disease amyloidosis models. bioRxiv 2020.

25. Saito, T.; Matsuba, Y.; Mihira, N.; Takano, J.; Nilsson, P.; Itohara, S.; Iwata, N.; Saido, T.C. Single App knock-in mouse models of Alzheimer's disease. Nat Neurosci 2014, 17, 661-663, doi:10.1038/nn.3697.

26. Serneels, L.; T'Syen, D.; Perez-Benito, L.; Theys, T.; Holt, M.G.; De Strooper, B. Modeling the $\beta$-secretase cleavage site and humanizing amyloid-beta precursor protein in rat and mouse to study Alzheimer's disease. Molecular Neurodegeneration 2020, 15, 60, doi:10.1186/s13024-020-00399-z.

27. Sato, K.; Watamura, N.; Fujioka, R.; Mihira, N.; Sekiguchi, M.; Nagata, K.; Ohshima, T.; Saito, T.; Saido, T.C.; Sasaguri, H. A 3(rd) generation mouse model of Alzheimer's disease shows early and increased cored plaque pathology composed of wild-type human amyloid $\beta$ peptide. J Biol Chem 2021, 101004, doi:10.1016/j.jbc.2021.101004.

28. Baglietto-Vargas, D.; Forner, S.; Cai, L.; Martini, A.C.; Trujillo-Estrada, L.; Swarup, V.; Nguyen, M.M.T.; Do Huynh, K.; Javonillo, D.I.; Tran, K.M.; et al. Generation of a humanized $\mathrm{A} \beta$ expressing mouse demonstrating aspects of Alzheimer's disease-like pathology. Nature Communications 2021, 12, 2421, doi:10.1038/s41467-021-22624-z.

29. Latimer, C.S.; Shively, C.A.; Keene, C.D.; Jorgensen, M.J.; Andrews, R.N.; Register, T.C.; Montine, T.J.; Wilson, A.M.; Neth, B.J.; Mintz, A.; et al. A nonhuman primate model of early Alzheimer's disease pathologic change: Implications for disease pathogenesis. Alzheimer's \& dementia : the journal of the Alzheimer's Association 2019, 15, 93-105, doi:10.1016/j.jalz.2018.06.3057.

30. Whitesell, J.D.; Buckley, A.R.; Knox, J.E.; Kuan, L.; Graddis, N.; Pelos, A.; Mukora, A.; Wakeman, W.; Bohn, P.; Ho, A.; et al. Whole brain imaging reveals distinct spatial patterns of amyloid beta deposition in three mouse models of Alzheimer's disease. J Comp Neurol 2019, 527, 2122-2145, doi:10.1002/cne.24555.

31. Liu, P.; Reichl, J.H.; Rao, E.R.; McNellis, B.M.; Huang, E.S.; Hemmy, L.S.; Forster, C.L.; Kuskowski, M.A.; Borchelt, D.R.; Vassar, R.; et al. Quantitative Comparison of Dense-Core Amyloid Plaque Accumulation in Amyloid- $\beta$ Protein Precursor Transgenic Mice. $J$ Alzheimers Dis 2017, 56, 743-761, doi:10.3233/jad-161027.

32. Sasaguri, H.; Nilsson, P.; Hashimoto, S.; Nagata, K.; Saito, T.; De Strooper, B.; Hardy, J.; Vassar, R.; Winblad, B.; Saido, T.C. APP mouse models for Alzheimer's disease preclinical studies. Embo j 2017, 36, 2473-2487, doi:10.15252/embj.201797397.

33. Robbins, E.M.; Betensky, R.A.; Domnitz, S.B.; Purcell, S.M.; Garcia-Alloza, M.; Greenberg, C.; Rebeck, G.W.; Hyman, B.T.; Greenberg, S.M.; Frosch, M.P.; et al. Kinetics of cerebral amyloid angiopathy progression in a transgenic mouse model of Alzheimer disease. $J$ Neurosci 2006, 26, 365-371, doi:10.1523/jneurosci.3854-05.2006. 
34. Jäkel, L.; Van Nostrand, W.E.; Nicoll, J.A.R.; Werring, D.J.; Verbeek, M.M. Animal models of cerebral amyloid angiopathy. Clin Sci (Lond) 2017, 131, 2469-2488, doi:10.1042/cs20170033.

35. Cheng, Y.; Ono, M.; Kimura, H.; Kagawa, S.; Nishii, R.; Saji, H. A novel 18F-labeled pyridyl benzofuran derivative for imaging of $\beta$-amyloid plaques in Alzheimer's brains. Bioorganic \& Medicinal Chemistry Letters 2010, 20, 6141-6144, doi:https://doi.org/10.1016/j.bmcl.2010.08.016.

36. Hostetler, E.D.; Sanabria-Bohórquez, S.; Fan, H.; Zeng, Z.; Gammage, L.; Miller, P.; O'Malley, S.; Connolly, B.; Mulhearn, J.; Harrison, S.T.; et al. [18F]Fluoroazabenzoxazoles as potential amyloid plaque PET tracers: synthesis and in vivo evaluation in rhesus monkey. Nucl Med Biol 2011, 38, 1193-1203, doi:10.1016/j.nucmedbio.2011.04.004.

37. Snellman, A.; Rokka, J.; Lopez-Picon, F.R.; Helin, S.; Re, F.; Loyttyniemi, E.; Pihlaja, R.; Forloni, G.; Salmona, M.; Masserini, M.; et al. Applicability of [(11)C]PIB micro-PET imaging for in vivo follow-up of anti-amyloid treatment effects in APP23 mouse model. Neurobiol Aging 2017, 57, 84-94, doi:10.1016/j.neurobiolaging.2017.05.008.

38. Oh, S.J.; Lee, H.-J.; Kang, K.J.; Han, S.J.; Lee, Y.J.; Lee, K.C.; Lim, S.M.; Chi, D.Y.; Kim, K.M.; Park, J.-A.; et al. Early Detection of $\mathrm{A}<\mathrm{i}>\beta</ \mathrm{i}>$ Deposition in the 5xFAD Mouse by Amyloid PET. Contrast Media \& Molecular Imaging 2018, 2018, 5272014, doi:10.1155/2018/5272014.

39. Oh, S.J.; Kim, M.H.; Han, S.J.; Kang, K.J.; Ko, I.O.; Kim, Y.; Park, J.-A.; Choi, J.Y.; Lee, K.C.; Chi, D.Y.; et al. Preliminary PET Study of 18F-FC119S in Normal and Alzheimer's Disease Models. Molecular Pharmaceutics 2017, 14, 3114-3120, doi:10.1021/acs.molpharmaceut.7b00351.

40. Yousefi, B.H.; von Reutern, B.; Scherubl, D.; Manook, A.; Schwaiger, M.; Grimmer, T.; Henriksen, G.; Forster, S.; Drzezga, A.; Wester, H.J. FIBT versus florbetaben and PiB: a preclinical comparison study with amyloid-PET in transgenic mice. EJNMMI Res 2015, 5, 20, doi:10.1186/s13550-015-0090-6.

41. Snellman, A.; Rokka, J.; Lopez-Picon, F.R.; Eskola, O.; Wilson, I.; Farrar, G.; Scheinin, M.; Solin, O.; Rinne, J.O.; Haaparanta-Solin, M. Pharmacokinetics of $\left[{ }^{18} \mathrm{~F}\right]$ flutemetamol in wildtype rodents and its binding to beta amyloid deposits in a mouse model of Alzheimer's disease. Eur J Nucl Med Mol Imaging 2012, 39, 1784-1795, doi:10.1007/s00259-012-2178-9.

42. Snellman, A.; Rokka, J.; López-Picón, F.R.; Eskola, O.; Salmona, M.; Forloni, G.; Scheinin, M.; Solin, O.; Rinne, J.O.; Haaparanta-Solin, M. In vivo PET imaging of beta-amyloid deposition in mouse models of Alzheimer's disease with a high specific activity PET imaging agent [18F]flutemetamol. EJNMMI Research 2014, 4, 37, doi:10.1186/s13550-014-0037-3.

43. Huang, Y.; Cho, H.-J.; Bandara, N.; Sun, L.; Tran, D.; Rogers, B.E.; Mirica, L.M. Metalchelating benzothiazole multifunctional compounds for the modulation and 64Cu PET imaging of A $\beta$ aggregation. Chemical Science 2020, 11, 7789-7799, doi:10.1039/D0SC02641G.

44. Xu, M.; Guo, J.; Gu, J.; Zhang, L.; Liu, Z.; Ding, L.; Fu, H.; Ma, Y.; Liang, S.; Wang, H. Preclinical and clinical study on [18F]DRKXH1: a novel $\beta$-amyloid PET tracer for Alzheimer's disease. European Journal of Nuclear Medicine and Molecular Imaging 2021, doi:10.1007/s00259-021-05421-0. 
45. Liang, S.H.; Holland, J.P.; Stephenson, N.A.; Kassenbrock, A.; Rotstein, B.H.; Daignault, C.P.; Lewis, R.; Collier, L.; Hooker, J.M.; Vasdev, N. PET neuroimaging studies of $[(18) \mathrm{F}] \mathrm{CABS} 13$ in a double transgenic mouse model of Alzheimer's disease and nonhuman primates. ACS chemical neuroscience 2015, 6, 535-541, doi:10.1021/acschemneuro.5b00055.

46. Juréus, A.; Swahn, B.M.; Sandell, J.; Jeppsson, F.; Johnson, A.E.; Johnström, P.; Neelissen, J.A.; Sunnemark, D.; Farde, L.; Svensson, S.P. Characterization of AZD4694, a novel fluorinated Abeta plaque neuroimaging PET radioligand. J Neurochem 2010, 114, 784-794, doi:10.1111/j.1471-4159.2010.06812.x.

47. Parent, M.J.; Zimmer, E.R.; Shin, M.; Kang, M.S.; Fonov, V.S.; Mathieu, A.; Aliaga, A.; Kostikov, A.; Do Carmo, S.; Dea, D.; et al. Multimodal Imaging in Rat Model Recapitulates Alzheimer's Disease Biomarkers Abnormalities. J Neurosci 2017, 37, 12263-12271, doi:10.1523/jneurosci.1346-17.2017.

48. Cho, H.J.; Huynh, T.T.; Rogers, B.E.; Mirica, L.M. Design of a multivalent bifunctional chelator for diagnostic (64)Cu PET imaging in Alzheimer's disease. Proc Natl Acad Sci U S A 2020, 117, 30928-30933, doi:10.1073/pnas.2014058117.

49. Poisnel, G.; Dhilly, M.; Moustié, O.; Delamare, J.; Abbas, A.; Guilloteau, D.; Barré, L. PET imaging with [18F]AV-45 in an APP/PS1-21 murine model of amyloid plaque deposition. Neurobiology of Aging 2012, 33, 2561-2571, doi:https://doi.org/10.1016/j.neurobiolaging.2011.12.024.

50. $\quad$ Rodriguez-Vieitez, E.; Ni, R.; Gulyas, B.; Toth, M.; Haggkvist, J.; Halldin, C.; Voytenko, L.; Marutle, A.; Nordberg, A. Astrocytosis precedes amyloid plaque deposition in Alzheimer APPswe transgenic mouse brain: a correlative positron emission tomography and in vitro imaging study. European journal of nuclear medicine and molecular imaging 2015, 42, 11191132 doi:10.1007/s00259-015-3047-0.

51. Ni, R.; Gillberg, P.-G.; Bogdanovic, N.; Viitanen, M.; Myllykangas, L.; Nennesmo, I.; Långström, B.; Nordberg, A. Amyloid tracers binding sites in autosomal dominant and sporadic Alzheimer's disease. Alzheimer's \& Dementia 2017, 13, 419-430, doi:https://doi.org/10.1016/j.jalz.2016.08.006.

52. Ni, R.; Röjdner, J.; Voytenko, L.; Dyrks, T.; Thiele, A.; Marutle, A.; Nordberg, A. In vitro Characterization of the Regional Binding Distribution of Amyloid PET Tracer Florbetaben and the Glia Tracers Deprenyl and PK11195 in Autopsy Alzheimer's Brain Tissue. $J$ Alzheimers Dis 2021, 80, 1723-1737, doi:10.3233/jad-201344.

53. Sehlin, D.; Fang, X.T.; Cato, L.; Antoni, G.; Lannfelt, L.; Syvanen, S. Antibody-based PET imaging of amyloid beta in mouse models of Alzheimer's disease. Nature communications 2016, 7, 10759, doi:10.1038/ncomms10759.

54. Tournier, B.B.; Tsartsalis, S.; Rigaud, D.; Fossey, C.; Cailly, T.; Fabis, F.; Pham, T.; Grégoire, M.C.; Kövari, E.; Moulin-Sallanon, M.; et al. TSPO and amyloid deposits in subregions of the hippocampus in the 3xTgAD mouse model of Alzheimer's disease. Neurobiol Dis 2019, 121, 95-105, doi:10.1016/j.nbd.2018.09.022.

55. Chen, C.J.; Bando, K.; Ashino, H.; Taguchi, K.; Shiraishi, H.; Shima, K.; Fujimoto, O.; Kitamura, C.; Morimoto, Y.; Kasahara, H.; et al. Biological evaluation of the radioiodinated imidazo[1,2-a]pyridine derivative DRK092 for amyloid- $\beta$ imaging in mouse model of Alzheimer's disease. Neurosci Lett 2014, 581, 103-108, doi:10.1016/j.neulet.2014.08.036. 
56. Roney, C.A.; Arora, V.; Kulkarni, P.V.; Antich, P.P.; Bonte, F.J. Nanoparticulate radiolabelled quinolines detect amyloid plaques in mouse models of Alzheimer's disease. Int $J$ Alzheimers Dis 2010, 2009, doi:10.4061/2009/481031.

57. Liu, Y.; Yang, Y.; Sun, M.; Cui, M.; Fu, Y.; Lin, Y.; Li, Z.; Nie, L. Highly specific noninvasive photoacoustic and positron emission tomography of brain plaque with functionalized croconium dye labeled by a radiotracer. Chem Sci 2017, 8, 2710-2716, doi: $10.1039 / \mathrm{c} 6 \mathrm{sc} 04798 \mathrm{j}$.

58. Razansky, D.; Klohs, J.; Ni, R. Multi-scale optoacoustic molecular imaging of brain diseases. Eur J Nucl Med Mol Imaging 2021, doi:10.1007/s00259-021-05207-4.

59. Shi, X.-f.; Ji, B.; Kong, Y.; Guan, Y.; Ni, R. Multimodal Contrast Agents for Optoacoustic Brain Imaging in Small Animals. Frontiers in Bioengineering and Biotechnology 2021, 9 , 764.

60. Snellman, A.; López-Picón, F.R.; Rokka, J.; Salmona, M.; Forloni, G.; Scheinin, M.; Solin, O.; Rinne, J.O.; Haaparanta-Solin, M. Longitudinal amyloid imaging in mouse brain with 11C-PIB: comparison of APP23, Tg2576, and APPswe-PS1dE9 mouse models of Alzheimer disease. J Nucl Med 2013, 54, 1434-1441, doi:10.2967/jnumed.112.110163.

61. Brendel, M.; Jaworska, A.; Grießinger, E.; Rötzer, C.; Burgold, S.; Gildehaus, F.J.; Carlsen, J.; Cumming, P.; Baumann, K.; Haass, C.; et al. Cross-sectional comparison of small animal [18F]-florbetaben amyloid-PET between transgenic AD mouse models. PLoS One 2015, 10, e0116678, doi:10.1371/journal.pone.0116678.

62. Son, H.J.; Jeong, Y.J.; Yoon, H.J.; Lee, S.Y.; Choi, G.-E.; Park, J.-A.; Kim, M.H.; Lee, K.C.; Lee, Y.J.; Kim, M.K.; et al. Assessment of brain beta-amyloid deposition in transgenic mouse models of Alzheimer's disease with PET imaging agents (18)F-flutemetamol and (18)Fflorbetaben. BMC neuroscience 2018, 19, 45-45, doi:10.1186/s12868-018-0447-7.

63. Sacher, C.; Blume, T.; Beyer, L.; Biechele, G.; Sauerbeck, J.; Eckenweber, F.; Deussing, M.; Focke, C.; Parhizkar, S.; Lindner, S.; et al. Asymmetry of Fibrillar Plaque Burden in Amyloid Mouse Models. J Nucl Med 2020, 61, 1825-1831, doi:10.2967/jnumed.120.242750.

64. Catafau, A.M.; Bullich, S. Amyloid PET imaging: applications beyond Alzheimer's disease. Clinical and translational imaging 2015, 3, 39-55, doi:10.1007/s40336-014-0098-3.

65. Han, B.H.; Zhou, M.-1.; Vellimana, A.K.; Milner, E.; Kim, D.H.; Greenberg, J.K.; Chu, W.; Mach, R.H.; Zipfel, G.J. Resorufin analogs preferentially bind cerebrovascular amyloid: potential use as imaging ligands for cerebral amyloid angiopathy. Molecular Neurodegeneration 2011, 6, 86, doi:10.1186/1750-1326-6-86.

66. Abrahamson, E.E.; Stehouwer, J.S.; Vazquez, A.L.; Huang, G.-F.; Mason, N.S.; Lopresti, B.J.; Klunk, W.E.; Mathis, C.A.; Ikonomovic, M.D. Development of a PET radioligand selective for cerebral amyloid angiopathy. Nuclear Medicine and Biology 2021, 92, 85-96, doi:https://doi.org/10.1016/j.nucmedbio.2020.05.001.

67. Iikuni, S.; Ono, M.; Watanabe, H.; Matsumura, K.; Yoshimura, M.; Kimura, H.; IshibashiUeda, H.; Okamoto, Y.; Ihara, M.; Saji, H. Imaging of Cerebral Amyloid Angiopathy with Bivalent 99mTc-Hydroxamamide Complexes. Scientific Reports 2016, 6, 25990, doi:10.1038/srep25990.

68. Biechele, G.; Sebastian Monasor, L.; Wind, K.; Blume, T.; Parhizkar, S.; Arzberger, T.; Sacher, C.; Beyer, L.; Eckenweber, F.; Gildehaus, F.J.; et al. Glitter in the Darkness? Non- 
fibrillar $\beta$-amyloid Plaque Components Significantly Impact the $\beta$-amyloid PET Signal in Mouse Models of Alzheimer's Disease. J Nucl Med 2021, doi:10.2967/jnumed.120.261858.

69. Sehlin, D.; Syvänen, S. Engineered antibodies: new possibilities for brain PET? Eur J Nucl Med Mol Imaging 2019, 46, 2848-2858, doi:10.1007/s00259-019-04426-0.

70. $\quad$ Meier, S.R.; Sehlin, D.; Roshanbin, S.; Lim Falk, V.; Saito, T.; Saido, T.C.; Neumann, U.; Rokka, J.; Eriksson, J.; Syvanen, S. (11)C-PIB and (124)I-antibody PET provide differing estimates of brain amyloid-beta after therapeutic intervention. J Nucl Med 2021, doi:10.2967/jnumed.121.262083.

71. Brendel, M.; Jaworska, A.; Herms, J.; Trambauer, J.; Rötzer, C.; Gildehaus, F.J.; Carlsen, J.; Cumming, P.; Bylund, J.; Luebbers, T.; et al. Amyloid-PET predicts inhibition of de novo plaque formation upon chronic $\gamma$-secretase modulator treatment. Mol Psychiatry 2015, 20, 1179-1187, doi:10.1038/mp.2015.74.

72. Brendel, M.; Jaworska, A.; Overhoff, F.; Blume, T.; Probst, F.; Gildehaus, F.J.; Bartenstein, P.; Haass, C.; Bohrmann, B.; Herms, J.; et al. Efficacy of chronic BACE1 inhibition in PS2APP mice depends on the regional $A \beta$ deposition rate and plaque burden at treatment initiation. Theranostics 2018, 8, 4957-4968, doi:10.7150/thno.27868.

73. Deleye, S.; Waldron, A.M.; Verhaeghe, J.; Bottelbergs, A.; Wyffels, L.; Van Broeck, B.; Langlois, X.; Schmidt, M.; Stroobants, S.; Staelens, S. Evaluation of Small-Animal PET Outcome Measures to Detect Disease Modification Induced by BACE Inhibition in a Transgenic Mouse Model of Alzheimer Disease. J Nucl Med 2017, 58, 1977-1983, doi:10.2967/jnumed.116.187625.

74. Xu, Y.; Wang, C.; Wey, H.-Y.; Liang, Y.; Chen, Z.; Choi, S.H.; Ran, C.; Rynearson, K.D.; Bernales, D.R.; Koegel, R.E.; et al. Molecular imaging of Alzheimer's disease-related gamma-secretase in mice and nonhuman primates. Journal of Experimental Medicine 2020, 217, doi:10.1084/jem.20182266.

75. An, Y.; Varma, V.R.; Varma, S.; Casanova, R.; Dammer, E.; Pletnikova, O.; Chia, C.W.; Egan, J.M.; Ferrucci, L.; Troncoso, J.; et al. Evidence for brain glucose dysregulation in Alzheimer's disease. Alzheimer's \& dementia : the journal of the Alzheimer's Association 2018, 14, 318-329, doi:10.1016/j.jalz.2017.09.011.

76. McIntosh, E.C.; Nation, D.A. Importance of Treatment Status in Links Between Type 2 Diabetes and Alzheimer's Disease. Diabetes Care 2019, 42, 972-979, doi:10.2337/dc18-1399.

77. Foster, N.L.; Heidebrink, J.L.; Clark, C.M.; Jagust, W.J.; Arnold, S.E.; Barbas, N.R.; DeCarli, C.S.; Turner, R.S.; Koeppe, R.A.; Higdon, R.; et al. FDG-PET improves accuracy in distinguishing frontotemporal dementia and Alzheimer's disease. Brain 2007, 130, 26162635, doi:10.1093/brain/awm177.

78. Bouter, C.; Henniges, P.; Franke, T.N.; Irwin, C.; Sahlmann, C.O.; Sichler, M.E.; Beindorff, N.; Bayer, T.A.; Bouter, Y. (18)F-FDG-PET Detects Drastic Changes in Brain Metabolism in the Tg4-42 Model of Alzheimer's Disease. Front Aging Neurosci 2018, 10, 425, doi:10.3389/fnagi.2018.00425.

79. Kuntner, C.; Kesner, A.L.; Bauer, M.; Kremslehner, R.; Wanek, T.; Mandler, M.; Karch, R.; Stanek, J.; Wolf, T.; Müller, M.; et al. Limitations of small animal PET imaging with [18F]FDDNP and FDG for quantitative studies in a transgenic mouse model of Alzheimer's disease. Mol Imaging Biol 2009, 11, 236-240, doi:10.1007/s11307-009-0198-z. 
80. Belfiore, R.; Rodin, A.; Ferreira, E.; Velazquez, R.; Branca, C.; Caccamo, A.; Oddo, S. Temporal and regional progression of Alzheimer's disease-like pathology in 3xTg-AD mice. Aging Cell 2019, 18, e12873, doi:10.1111/acel.12873.

81. Frost, G.R.; Longo, V.; Li, T.; Jonas, L.A.; Judenhofer, M.; Cherry, S.; Koutcher, J.; Lekaye, C.; Zanzonico, P.; Li, Y.-M. Hybrid PET/MRI enables high-spatial resolution, quantitative imaging of amyloid plaques in an Alzheimer's disease mouse model. Scientific Reports 2020, 10, 10379, doi:10.1038/s41598-020-67284-z.

82. Waldron, A.M.; Wintmolders, C.; Bottelbergs, A.; Kelley, J.B.; Schmidt, M.E.; Stroobants, S.; Langlois, X.; Staelens, S. In vivo molecular neuroimaging of glucose utilization and its association with fibrillar amyloid- $\beta$ load in aged APPPS1-21 mice. Alzheimers Res Ther 2015, 7, 76, doi:10.1186/s13195-015-0158-6.

83. Adlimoghaddam, A.; Snow, W.M.; Stortz, G.; Perez, C.; Djordjevic, J.; Goertzen, A.L.; Ko, J.H.; Albensi, B.C. Regional hypometabolism in the 3xTg mouse model of Alzheimer's disease. Neurobiol Dis 2019, 127, 264-277, doi:10.1016/j.nbd.2019.03.008.

84. Wagner, J.M.; Sichler, M.E.; Schleicher, E.M.; Franke, T.N.; Irwin, C.; Löw, M.J.; Beindorff, N.; Bouter, C.; Bayer, T.A.; Bouter, Y. Analysis of Motor Function in the Tg4-42 Mouse Model of Alzheimer's Disease. Frontiers in behavioral neuroscience 2019, 13, 107-107, doi:10.3389/fnbeh.2019.00107.

85. Rojas, S.; Herance, J.R.; Gispert, J.D.; Abad, S.; Torrent, E.; Jiménez, X.; Pareto, D.; Perpiña, U.; Sarroca, S.; Rodríguez, E.; et al. In vivo evaluation of amyloid deposition and brain glucose metabolism of 5XFAD mice using positron emission tomography. Neurobiol Aging 2013, 34, 1790-1798, doi:10.1016/j.neurobiolaging.2012.12.027.

86. Maier, F.C.; Wehrl, H.F.; Schmid, A.M.; Mannheim, J.G.; Wiehr, S.; Lerdkrai, C.; Calaminus, C.; Stahlschmidt, A.; Ye, L.; Burnet, M.; et al. Longitudinal PET-MRI reveals $\beta$ amyloid deposition and $\mathrm{rCBF}$ dynamics and connects vascular amyloidosis to quantitative loss of perfusion. Nature Medicine 2014, 20, 1485-1492, doi:10.1038/nm.3734.

87. Brendel, M.; Probst, F.; Jaworska, A.; Overhoff, F.; Korzhova, V.; Albert, N.L.; Beck, R.; Lindner, S.; Gildehaus, F.J.; Baumann, K.; et al. Glial Activation and Glucose Metabolism in a Transgenic Amyloid Mouse Model: A Triple-Tracer PET Study. J Nucl Med 2016, 57, 954960, doi:10.2967/jnumed.115.167858.

88. Takkinen, J.S.; López-Picón, F.R.; Al Majidi, R.; Eskola, O.; Krzyczmonik, A.; Keller, T.; Löyttyniemi, E.; Solin, O.; Rinne, J.O.; Haaparanta-Solin, M. Brain energy metabolism and neuroinflammation in ageing APP/PS1-21 mice using longitudinal (18)F-FDG and (18)FDPA-714 PET imaging. J Cereb Blood Flow Metab 2017, 37, 2870-2882, doi:10.1177/0271678x16677990.

89. Tsukada, H.; Nishiyama, S.; Ohba, H.; Kanazawa, M.; Kakiuchi, T.; Harada, N. Comparing amyloid- $\beta$ deposition, neuroinflammation, glucose metabolism, and mitochondrial complex I activity in brain: a PET study in aged monkeys. Eur J Nucl Med Mol Imaging 2014, 41, 2127 2136, doi:10.1007/s00259-014-2821-8.

90. Snellman, A.; Takkinen, J.S.; López-Picón, F.R.; Eskola, O.; Solin, O.; Rinne, J.O.; Haaparanta-Solin, M. Effect of genotype and age on cerebral [18F]FDG uptake varies between transgenic APPSwe-PS1dE9 and Tg2576 mouse models of Alzheimer's disease. Scientific Reports 2019, 9, 5700, doi:10.1038/s41598-019-42074-4. 
91. DeKosky, S.T.; Scheff, S.W. Synapse loss in frontal cortex biopsies in Alzheimer's disease: correlation with cognitive severity. Ann Neurol 1990, 27, 457-464, doi:10.1002/ana.410270502.

92. Colom-Cadena, M.; Spires-Jones, T.; Zetterberg, H.; Blennow, K.; Caggiano, A.; DeKosky, S.T.; Fillit, H.; Harrison, J.E.; Schneider, L.S.; Scheltens, P.; et al. The clinical promise of biomarkers of synapse damage or loss in Alzheimer's disease. Alzheimers Res Ther 2020, 12, 21, doi:10.1186/s13195-020-00588-4.

93. Ni, R.; Ji, B.; Ono, M.; Sahara, N.; Zhang, M.R.; Aoki, I.; Nordberg, A.; Suhara, T.; Higuchi, M. Comparative In Vitro and In Vivo Quantifications of Pathologic Tau Deposits and Their Association with Neurodegeneration in Tauopathy Mouse Models. J Nucl Med 2018, 59, 960966, doi:10.2967/jnumed.117.201632.

94. Lynch, B.A.; Lambeng, N.; Nocka, K.; Kensel-Hammes, P.; Bajjalieh, S.M.; Matagne, A.; Fuks, B. The synaptic vesicle protein SV2A is the binding site for the antiepileptic drug levetiracetam. Proceedings of the National Academy of Sciences of the United States of America 2004, 101, 9861-9866, doi:10.1073/pnas.0308208101.

95. Kong, Y.; Huang, L.; Li, W.; Liu, X.; Zhou, Y.; Liu, C.; Zhang, S.; Xie, F.; Zhang, Z.; Jiang, D.; et al. The Synaptic Vesicle Protein 2A Interacts With Key Pathogenic Factors in Alzheimer's Disease: Implications for Treatment. Frontiers in cell and developmental biology 2021, 9, 609908-609908, doi:10.3389/fcell.2021.609908.

96. Bahri, M.A.; Plenevaux, A.; Aerts, J.; Bastin, C.; Becker, G.; Mercier, J.; Valade, A.; Buchanan, T.; Mestdagh, N.; Ledoux, D.; et al. Measuring brain synaptic vesicle protein 2A with positron emission tomography and [18F]UCB-H. Alzheimer's \& Dementia:

Translational Research \& Clinical Interventions 2017, 3, 481-486, doi:https://doi.org/10.1016/j.trci.2017.08.004.

97. Naganawa, M.; Li, S.; Nabulsi, N.; Henry, S.; Zheng, M.Q.; Pracitto, R.; Cai, Z.; Gao, H.; Kapinos, M.; Labaree, D.; et al. First-in-Human Evaluation of (18)F-SynVesT-1, a Radioligand for PET Imaging of Synaptic Vesicle Glycoprotein 2A. J Nucl Med 2021, 62, 561-567, doi:10.2967/jnumed.120.249144.

98. $\quad$ Li, S.; Cai, Z.; Wu, X.; Holden, D.; Pracitto, R.; Kapinos, M.; Gao, H.; Labaree, D.; Nabulsi, N.; Carson, R.E.; et al. Synthesis and in Vivo Evaluation of a Novel PET Radiotracer for Imaging of Synaptic Vesicle Glycoprotein 2A (SV2A) in Nonhuman Primates. ACS Chemical Neuroscience 2019, 10, 1544-1554, doi:10.1021/acschemneuro.8b00526.

99. Constantinescu, C.C.; Tresse, C.; Zheng, M.; Gouasmat, A.; Carroll, V.M.; Mistico, L.; Alagille, D.; Sandiego, C.M.; Papin, C.; Marek, K.; et al. Development and In Vivo Preclinical Imaging of Fluorine-18-Labeled Synaptic Vesicle Protein 2A (SV2A) PET Tracers. Molecular Imaging and Biology 2019, 21, 509-518, doi:10.1007/s11307-018-1260-5.

100. Chen, M.K.; Mecca, A.P.; Naganawa, M.; Finnema, S.J.; Toyonaga, T.; Lin, S.F.; Najafzadeh, S.; Ropchan, J.; Lu, Y.; McDonald, J.W.; et al. Assessing Synaptic Density in Alzheimer Disease With Synaptic Vesicle Glycoprotein 2A Positron Emission Tomographic Imaging. JAMA Neurol 2018, 75, 1215-1224, doi:10.1001/jamaneurol.2018.1836.

101. Finnema, S.J.; Nabulsi, N.B.; Eid, T.; Detyniecki, K.; Lin, S.F.; Chen, M.K.; Dhaher, R.; Matuskey, D.; Baum, E.; Holden, D.; et al. Imaging synaptic density in the living human brain. Sci Transl Med 2016, 8, 348ra396, doi:10.1126/scitranslmed.aaf6667. 
102. O’Dell, R.S.; Mecca, A.P.; Chen, M.-K.; Naganawa, M.; Toyonaga, T.; Lu, Y.; Godek, T.A.; Harris, J.E.; Bartlett, H.H.; Banks, E.R.; et al. Association of A $\beta$ deposition and regional synaptic density in early Alzheimer's disease: a PET imaging study with [11C]UCB-J. Alzheimer's Research \& Therapy 2021, 13, 11, doi:10.1186/s13195-020-00742-y.

103. Bertoglio, D.; Verhaeghe, J.; Miranda, A.; Kertesz, I.; Cybulska, K.; Korat, Š.; Wyffels, L.; Stroobants, S.; Mrzljak, L.; Liu, L.; et al. Validation and noninvasive kinetic modeling of [ 11 C]UCB-J PET imaging in mice. Journal of Cerebral Blood Flow \& Metabolism 2019, 40, 0271678X1986408, doi:10.1177/0271678X19864081.

104. Toyonaga, T.; Smith, L.M.; Finnema, S.J.; Gallezot, J.D.; Naganawa, M.; Bini, J.; Mulnix, T.; Cai, Z.; Ropchan, J.; Huang, Y.; et al. In Vivo Synaptic Density Imaging with (11)C-UCB-J Detects Treatment Effects of Saracatinib in a Mouse Model of Alzheimer Disease. J Nucl Med 2019, 60, 1780-1786, doi:10.2967/jnumed.118.223867.

105. Xiong, M.; Roshanbin, S.; Rokka, J.; Schlein, E.; Ingelsson, M.; Sehlin, D.; Eriksson, J.; Syvänen, S. In vivo imaging of synaptic density with [11C]UCB-J PET in two mouse models of neurodegenerative disease. NeuroImage 2021, 239, 118302, doi:https://doi.org/10.1016/j.neuroimage.2021.118302.

106. Cai, Z.; Li, S.; Zhang, W.; Pracitto, R.; Wu, X.; Baum, E.; Finnema, S.J.; Holden, D.; Toyonaga, T.; Lin, S.-f.; et al. Synthesis and Preclinical Evaluation of an 18F-Labeled Synaptic Vesicle Glycoprotein 2A PET Imaging Probe: [18F]SynVesT-2. ACS Chemical Neuroscience 2020, 11, 592-603, doi:10.1021/acschemneuro.9b00618.

107. Sadasivam, P.; Fang, X.T.; Toyonaga, T.; Lee, S.; Xu, Y.; Zheng, M.Q.; Spurrier, J.; Huang, Y.; Strittmatter, S.M.; Carson, R.E.; et al. Quantification of SV2A Binding in Rodent Brain Using [(18)F]SynVesT-1 and PET Imaging. Mol Imaging Biol 2021, 23, 372-381, doi:10.1007/s11307-020-01567-9.

108. Iacobucci, G.J.; Popescu, G.K. NMDA receptors: linking physiological output to biophysical operation. Nature Reviews Neuroscience 2017, 18, 236-249, doi:10.1038/nrn.2017.24.

109. Nedergaard, M.; Takano, T.; Hansen, A.J. Beyond the role of glutamate as a neurotransmitter. Nature Reviews Neuroscience 2002, 3, 748-755, doi:10.1038/nrn916.

110. Palop, J.J.; Mucke, L. Network abnormalities and interneuron dysfunction in Alzheimer disease. Nature Reviews Neuroscience 2016, 17, 777-792, doi:10.1038/nrn.2016.141.

111. Wang, R.; Reddy, P.H. Role of Glutamate and NMDA Receptors in Alzheimer's Disease. $J$ Alzheimers Dis 2017, 57, 1041-1048, doi:10.3233/jad-160763.

112. Tanzi, R.E. The synaptic Abeta hypothesis of Alzheimer disease. In Nat Neurosci; United States, 2005; Volume 8, pp. 977-979.

113. Snyder, E.M.; Nong, Y.; Almeida, C.G.; Paul, S.; Moran, T.; Choi, E.Y.; Nairn, A.C.; Salter, M.W.; Lombroso, P.J.; Gouras, G.K.; et al. Regulation of NMDA receptor trafficking by amyloid-beta. Nat Neurosci 2005, 8, 1051-1058, doi:10.1038/nn1503.

114. Shankar, G.M.; Bloodgood, B.L.; Townsend, M.; Walsh, D.M.; Selkoe, D.J.; Sabatini, B.L. Natural oligomers of the Alzheimer amyloid-beta protein induce reversible synapse loss by modulating an NMDA-type glutamate receptor-dependent signaling pathway. The Journal of neuroscience : the official journal of the Society for Neuroscience 2007, 27, 2866-2875, doi:10.1523/JNEUROSCI.4970-06.2007. 
115. Um, Ji W.; Kaufman, Adam C.; Kostylev, M.; Heiss, Jacqueline K.; Stagi, M.; Takahashi, H.; Kerrisk, Meghan E.; Vortmeyer, A.; Wisniewski, T.; Koleske, Anthony J.; et al. Metabotropic Glutamate Receptor 5 Is a Coreceptor for Alzheimer A $\beta$ Oligomer Bound to Cellular Prion Protein. Neuron 2013, 79, 887-902, doi:https://doi.org/10.1016/j.neuron.2013.06.036.

116. Reinders, N.R.; Pao, Y.; Renner, M.C.; da Silva-Matos, C.M.; Lodder, T.R.; Malinow, R.; Kessels, H.W. Amyloid- $\beta$ effects on synapses and memory require AMPA receptor subunit GluA3. Proc Natl Acad Sci U S A 2016, 113, E6526-e6534, doi:10.1073/pnas.1614249113.

117. Tanaka, H.; Sakaguchi, D.; Hirano, T. Amyloid- $\beta$ oligomers suppress subunit-specific glutamate receptor increase during LTP. Alzheimers Dement (N Y) 2019, 5, 797-808, doi:10.1016/j.trci.2019.10.003.

118. Zott, B.; Simon, M.M.; Hong, W.; Unger, F.; Chen-Engerer, H.J.; Frosch, M.P.; Sakmann, B.; Walsh, D.M.; Konnerth, A. A vicious cycle of $\beta$ amyloid-dependent neuronal hyperactivation. Science 2019, 365, 559-565, doi:10.1126/science.aay0198.

119. Hamilton, A.; Vasefi, M.; Vander Tuin, C.; McQuaid, R.J.; Anisman, H.; Ferguson, S.S. Chronic Pharmacological mGluR5 Inhibition Prevents Cognitive Impairment and Reduces Pathogenesis in an Alzheimer Disease Mouse Model. Cell Rep 2016, 15, 1859-1865, doi:10.1016/j.celrep.2016.04.077.

120. Miyazaki, T.; Nakajima, W.; Hatano, M.; Shibata, Y.; Kuroki, Y.; Arisawa, T.; Serizawa, A.; Sano, A.; Kogami, S.; Yamanoue, T.; et al. Visualization of AMPA receptors in living human brain with positron emission tomography. Nat Med 2020, 26, 281-288, doi:10.1038/s41591019-0723-9.

121. Takahata, K.; Kimura, Y.; Seki, C.; Tokunaga, M.; Ichise, M.; Kawamura, K.; Ono, M.; Kitamura, S.; Kubota, M.; Moriguchi, S.; et al. A human PET study of [11C]HMS011, a potential radioligand for AMPA receptors. EJNMMI Research 2017, 7, 63, doi:10.1186/s13550-017-0313-0.

122. Vibholm, A.K.; Landau, A.M.; Møller, A.; Jacobsen, J.; Vang, K.; Munk, O.L.; Orlowski, D.; Sørensen, J.C.; Brooks, D.J. NMDA receptor ion channel activation detected in vivo with [(18)F]GE-179 PET after electrical stimulation of rat hippocampus. J Cereb Blood Flow Metab 2021, 41, 1301-1312, doi:10.1177/0271678x20954928.

123. van der Aart, J.; Golla, S.S.V.; van der Pluijm, M.; Schwarte, L.A.; Schuit, R.C.; Klein, P.J.; Metaxas, A.; Windhorst, A.D.; Boellaard, R.; Lammertsma, A.A.; et al. First in human evaluation of $[18 \mathrm{~F}] \mathrm{PK}-209$, a PET ligand for the ion channel binding site of NMDA receptors. EJNMMI Research 2018, 8, 69, doi:10.1186/s13550-018-0424-2.

124. Krämer, S.D.; Betzel, T.; Mu, L.; Haider, A.; Herde, A.M.; Boninsegni, A.K.; Keller, C.; Szermerski, M.; Schibli, R.; Wünsch, B.; et al. Evaluation of (11)C-Me-NB1 as a Potential PET Radioligand for Measuring GluN2B-Containing NMDA Receptors, Drug Occupancy, and Receptor Cross Talk. J Nucl Med 2018, 59, 698-703, doi:10.2967/jnumed.117.200451.

125. Abd-Elrahman, K.S.; Albaker, A.; de Souza, J.M.; Ribeiro, F.M.; Schlossmacher, M.G.; Tiberi, M.; Hamilton, A.; Ferguson, S.S.G. A $\beta$ oligomers induce pathophysiological mGluR5 signaling in Alzheimer's disease model mice in a sex-selective manner. Sci Signal 2020, 13, doi:10.1126/scisignal.abd2494.

126. Wong, D.F.; Waterhouse, R.; Kuwabara, H.; Kim, J.; Brašić, J.R.; Chamroonrat, W.; Stabins, M.; Holt, D.P.; Dannals, R.F.; Hamill, T.G.; et al. 18F-FPEB, a PET radiopharmaceutical for quantifying metabotropic glutamate 5 receptors: a first-in-human study of radiochemical 
safety, biokinetics, and radiation dosimetry. $\mathrm{J} \mathrm{Nucl} \mathrm{Med} \mathrm{2013,} \mathrm{54,} \mathrm{388-396,}$ doi:10.2967/jnumed.112.107995.

127. Ametamey, S.M.; Kessler, L.J.; Honer, M.; Wyss, M.T.; Buck, A.; Hintermann, S.; Auberson, Y.P.; Gasparini, F.; Schubiger, P.A. Radiosynthesis and preclinical evaluation of 11CABP688 as a probe for imaging the metabotropic glutamate receptor subtype 5. $\mathrm{J} \mathrm{Nucl} \mathrm{Med}$ 2006, 47, 698-705.

128. Warnock, G.; Sommerauer, M.; Mu, L.; Pla Gonzalez, G.; Geistlich, S.; Treyer, V.; Schibli, R.; Buck, A.; Krämer, S.D.; Ametamey, S.M. A first-in-man PET study of [(18)F]PSS232, a fluorinated ABP688 derivative for imaging metabotropic glutamate receptor subtype 5. Eur J Nucl Med Mol Imaging 2018, 45, 1041-1051, doi:10.1007/s00259-017-3879-X.

129. Mecca, A.P.; McDonald, J.W.; Michalak, H.R.; Godek, T.A.; Harris, J.E.; Pugh, E.A.; Kemp, E.C.; Chen, M.K.; Salardini, A.; Nabulsi, N.B.; et al. PET imaging of mGluR5 in Alzheimer's disease. Alzheimers Res Ther 2020, 12, 15, doi:10.1186/s13195-020-0582-0.

130. Treyer, V.; Gietl, A.F.; Suliman, H.; Gruber, E.; Meyer, R.; Buchmann, A.; Johayem, A.; Unschuld, P.G.; Nitsch, R.M.; Buck, A.; et al. Reduced uptake of [11C]-ABP688, a PET tracer for metabolic glutamate receptor 5 in hippocampus and amygdala in Alzheimer's dementia. Brain and Behavior 2020, 10, e01632, doi:https://doi.org/10.1002/brb3.1632.

131. Lee, M.; Lee, H.J.; Jeong, Y.J.; Oh, S.J.; Kang, K.J.; Han, S.J.; Nam, K.R.; Lee, Y.J.; Lee, K.C.; Ryu, Y.H.; et al. Age dependency of mGluR5 availability in 5xFAD mice measured by PET. Neurobiol Aging 2019, 84, 208-216, doi:10.1016/j.neurobiolaging.2019.08.006.

132. Varlow, C.; Murrell, E.; Holland, J.P.; Kassenbrock, A.; Shannon, W.; Liang, S.H.; Vasdev, N.; Stephenson, N.A. Revisiting the Radiosynthesis of [(18)F]FPEB and Preliminary PET Imaging in a Mouse Model of Alzheimer's Disease. Molecules 2020, 25, doi:10.3390/molecules25040982.

133. Fang, X.T.; Eriksson, J.; Antoni, G.; Yngve, U.; Cato, L.; Lannfelt, L.; Sehlin, D.; Syvänen, S. Brain mGluR5 in mice with amyloid beta pathology studied with in vivo [11C]ABP688 PET imaging and ex vivo immunoblotting. Neuropharmacology 2017, 113, 293-300, doi:https://doi.org/10.1016/i.neuropharm.2016.10.009.

134. Nordberg, A. Nicotinic receptor abnormalities of Alzheimer's disease: therapeutic implications. Biol Psychiatry 2001, 49, 200-210, doi:10.1016/s0006-3223(00)01125-2.

135. Hampel, H.; Mesulam, M.M.; Cuello, A.C.; Farlow, M.R.; Giacobini, E.; Grossberg, G.T.; Khachaturian, A.S.; Vergallo, A.; Cavedo, E.; Snyder, P.J.; et al. The cholinergic system in the pathophysiology and treatment of Alzheimer's disease. Brain 2018, 141, 1917-1933, doi:10.1093/brain/awy132.

136. Wang, H.; Yu, M.; Ochani, M.; Amella, C.A.; Tanovic, M.; Susarla, S.; Li, J.H.; Yang, H.; Ulloa, L.; Al-Abed, Y.; et al. Nicotinic acetylcholine receptor alpha7 subunit is an essential regulator of inflammation. Nature 2003, 421, 384-388, doi:10.1038/nature01339.

137. Marutle, A.; Gillberg, P.G.; Bergfors, A.; Yu, W.F.; Ni, R.Q.; Nennesmo, I.; Voytenko, L.; Nordberg, A. H-3-Deprenyl and H-3-PIB autoradiography show different laminar distributions of astroglia and fibrillar beta-amyloid in Alzheimer brain. Journal of Neuroinflammation 2013, 10, doi:10.1186/1742-2094-10-90.

138. Ikonomovic, M.D.; Wecker, L.; Abrahamson, E.E.; Wuu, J.; Counts, S.E.; Ginsberg, S.D.; Mufson, E.J.; Dekosky, S.T. Cortical alpha7 nicotinic acetylcholine receptor and beta- 
amyloid levels in early Alzheimer disease. Arch Neurol 2009, 66, 646-651, doi:10.1001/archneurol.2009.46.

139. Yi, J.H.; Whitcomb, D.J.; Park, S.J.; Martinez-Perez, C.; Barbati, S.A.; Mitchell, S.J.; Cho, K. M1 muscarinic acetylcholine receptor dysfunction in moderate Alzheimer's disease pathology. Brain Commun 2020, 2, fcaa058, doi:10.1093/braincomms/fcaa058.

140. Ni, R.; Marutle, A.; Nordberg, A. Modulation of $\alpha 7$ nicotinic acetylcholine receptor and fibrillar amyloid- $\beta$ interactions in Alzheimer's disease brain. J Alzheimers Dis 2013, 33, 841851, doi:10.3233/jad-2012-121447.

141. Wang, H.-Y.; Stucky, A.; Liu, J.; Shen, C.; Trocme-Thibierge, C.; Morain, P. Dissociating beta-amyloid from alpha 7 nicotinic acetylcholine receptor by a novel therapeutic agent, $\mathrm{S}$ 24795, normalizes alpha 7 nicotinic acetylcholine and NMDA receptor function in Alzheimer's disease brain. The Journal of neuroscience : the official journal of the Society for Neuroscience 2009, 29, 10961-10973, doi:10.1523/JNEUROSCI.6088-08.2009.

142. Medeiros, R.; Castello, N.A.; Cheng, D.; Kitazawa, M.; Baglietto-Vargas, D.; Green, K.N.; Esbenshade, T.A.; Bitner, R.S.; Decker, M.W.; LaFerla, F.M. $\alpha 7$ Nicotinic receptor agonist enhances cognition in aged 3xTg-AD mice with robust plaques and tangles. Am J Pathol 2014, 184, 520-529, doi:10.1016/j.ajpath.2013.10.010.

143. George, A.A.; Vieira, J.M.; Xavier-Jackson, C.; Gee, M.T.; Cirrito, J.R.; Bimonte-Nelson, H.A.; Picciotto, M.R.; Lukas, R.J.; Whiteaker, P. Implications of Oligomeric Amyloid-Beta

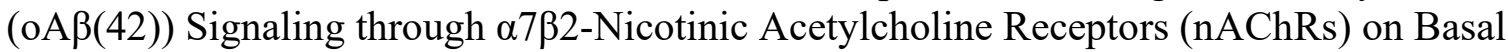
Forebrain Cholinergic Neuronal Intrinsic Excitability and Cognitive Decline. J Neurosci 2021, 41, 555-575, doi:10.1523/jneurosci.0876-20.2020.

144. Ettrup, A.; Mikkelsen, J.D.; Lehel, S.; Madsen, J.; Nielsen, E.; Palner, M.; Timmermann, D.B.; Peters, D.; Knudsen, G.M. 11C-NS14492 as a novel PET radioligand for imaging cerebral alpha7 nicotinic acetylcholine receptors: in vivo evaluation and drug occupancy measurements. J Nucl Med 2011, 52, 1449-1456, doi:10.2967/jnumed.111.088815.

145. Nishiyama, S.; Ohba, H.; Kanazawa, M.; Kakiuchi, T.; Tsukada, H. Comparing a7 nicotinic acetylcholine receptor binding, amyloid- $\beta$ deposition, and mitochondria complex-I function in living brain: A PET study in aged monkeys. Synapse 2015, 69, 475-483, doi:10.1002/syn.21842.

146. Gao, Y.; Kellar, K.J.; Yasuda, R.P.; Tran, T.; Xiao, Y.; Dannals, R.F.; Horti, A.G. Derivatives of dibenzothiophene for positron emission tomography imaging of $\alpha 7$-nicotinic acetylcholine receptors. J Med Chem 2013, 56, 7574-7589, doi:10.1021/jm401184f.

147. Yamamoto, S.; Nishiyama, S.; Kawamata, M.; Ohba, H.; Wakuda, T.; Takei, N.; Tsukada, H.; Domino, E.F. Muscarinic Receptor Occupancy and Cognitive Impairment: A PET Study with $[11 \mathrm{C}](+) 3-\mathrm{MPB}$ and Scopolamine in Conscious Monkeys. Neuropsychopharmacology 2011, 36, 1455-1465, doi:10.1038/npp.2011.31.

148. Rowe, C.C.; Krishnadas, N.; Ackermann, U.; Doré, V.; Goh, R.Y.W.; Guzman, R.; Chong, L.; Bozinovski, S.; Mulligan, R.; Kanaan, R.; et al. PET Imaging of brain muscarinic receptors with 18F-Fluorobenzyl-Dexetimide: A first in human study. Psychiatry Research: Neuroimaging 2021, 316, 111354, doi:https://doi.org/10.1016/j.pscychresns.2021.111354.

149. Nabulsi, N.B.; Holden, D.; Zheng, M.Q.; Bois, F.; Lin, S.F.; Najafzadeh, S.; Gao, H.; Ropchan, J.; Lara-Jaime, T.; Labaree, D.; et al. Evaluation of (11)C-LSN3172176 as a Novel 
PET Tracer for Imaging M(1) Muscarinic Acetylcholine Receptors in Nonhuman Primates. $J$ Nucl Med 2019, 60, 1147-1153, doi:10.2967/jnumed.118.222034.

150. Tong, L.; Li, W.; Lo, M.M.-C.; Gao, X.; Wai, J.M.-C.; Rudd, M.; Tellers, D.; Joshi, A.; Zeng, Z.; Miller, P.; et al. Discovery of [11C]MK-6884: A Positron Emission Tomography (PET) Imaging Agent for the Study of M4Muscarinic Receptor Positive Allosteric Modulators (PAMs) in Neurodegenerative Diseases. Journal of Medicinal Chemistry 2020, 63, 24112425, doi:10.1021/acs.jmedchem.9b01406.

151. Kadir, A.; Almkvist, O.; Wall, A.; Långström, B.; Nordberg, A. PET imaging of cortical 11Cnicotine binding correlates with the cognitive function of attention in Alzheimer's disease. Psychopharmacology (Berl) 2006, 188, 509-520, doi:10.1007/s00213-006-0447-7.

152. Chaney, A.M.; Lopez-Picon, F.R.; Serrière, S.; Wang, R.; Bochicchio, D.; Webb, S.D.; Vandesquille, M.; Harte, M.K.; Georgiadou, C.; Lawrence, C.; et al. Prodromal neuroinflammatory, cholinergic and metabolite dysfunction detected by PET and MRS in the TgF344-AD transgenic rat model of AD: a collaborative multi-modal study. Theranostics 2021, 11, 6644-6667, doi:10.7150/thno.56059.

153. Rejc, L.; Gómez-Vallejo, V.; Joya, A.; Moreno, O.; Egimendia, A.; Castellnou, P.; RíosAnglada, X.; Cossío, U.; Baz, Z.; Passannante, R.; et al. Longitudinal evaluation of a novel BChE PET tracer as an early in vivo biomarker in the brain of a mouse model for Alzheimer disease. Theranostics 2021, 11, 6542-6559, doi:10.7150/thno.54589.

154. Heneka, M.T.; Ramanathan, M.; Jacobs, A.H.; Dumitrescu-Ozimek, L.; Bilkei-Gorzo, A.; Debeir, T.; Sastre, M.; Galldiks, N.; Zimmer, A.; Hoehn, M.; et al. Locus ceruleus degeneration promotes Alzheimer pathogenesis in amyloid precursor protein 23 transgenic mice. J Neurosci 2006, 26, 1343-1354, doi:10.1523/jneurosci.4236-05.2006.

155. Montagne, A.; Nikolakopoulou, A.M.; Huuskonen, M.T.; Sagare, A.P.; Lawson, E.J.; Lazic, D.; Rege, S.V.; Grond, A.; Zuniga, E.; Barnes, S.R.; et al. APOE4 accelerates advanced-stage vascular and neurodegenerative disorder in old Alzheimer's mice via cyclophilin A independently of amyloid- $\beta$. Nature Aging 2021, 1, 506-520, doi:10.1038/s43587-021-00073$\mathrm{Z}$.

156. Montagne, A.; Nation, D.A.; Sagare, A.P.; Barisano, G.; Sweeney, M.D.; Chakhoyan, A.; Pachicano, M.; Joe, E.; Nelson, A.R.; D'Orazio, L.M.; et al. APOE4 leads to blood-brain barrier dysfunction predicting cognitive decline. Nature 2020, 581, 71-76, doi:10.1038/s41586-020-2247-3.

157. Bien-Ly, N.; Boswell, C.A.; Jeet, S.; Beach, T.G.; Hoyte, K.; Luk, W.; Shihadeh, V.; Ulufatu, S.; Foreman, O.; Lu, Y.; et al. Lack of Widespread BBB Disruption in Alzheimer's Disease Models: Focus on Therapeutic Antibodies. Neuron 2015, 88, 289-297, doi:10.1016/j.neuron.2015.09.036.

158. Merlini, M.; Meyer, E.P.; Ulmann-Schuler, A.; Nitsch, R.M. Vascular $\beta$-amyloid and early astrocyte alterations impair cerebrovascular function and cerebral metabolism in transgenic arcA $\beta$ mice. Acta Neuropathol 2011, 122, 293-311, doi:10.1007/s00401-011-0834-y.

159. Erdö, F.; Denes, L.; de Lange, E. Age-associated physiological and pathological changes at the blood-brain barrier: A review. J Cereb Blood Flow Metab 2017, 37, 4-24, doi:10.1177/0271678x16679420.

160. Cirrito, J.R.; Deane, R.; Fagan, A.M.; Spinner, M.L.; Parsadanian, M.; Finn, M.B.; Jiang, H.; Prior, J.L.; Sagare, A.; Bales, K.R.; et al. P-glycoprotein deficiency at the blood-brain barrier 
increases amyloid-beta deposition in an Alzheimer disease mouse model. The Journal of clinical investigation 2005, 115, 3285-3290, doi:10.1172/JCI25247.

161. Zoufal, V.; Wanek, T.; Krohn, M.; Mairinger, S.; Filip, T.; Sauberer, M.; Stanek, J.; Pekar, T.; Bauer, M.; Pahnke, J.; et al. Age dependency of cerebral P-glycoprotein function in wildtype and APPPS1 mice measured with PET. J Cereb Blood Flow Metab 2020, 40, 150-162, doi: $10.1177 / 0271678 \times 18806640$.

162. Zoufal, V.; Mairinger, S.; Brackhan, M.; Krohn, M.; Filip, T.; Sauberer, M.; Stanek, J.; Wanek, T.; Tournier, N.; Bauer, M.; et al. Imaging P-Glycoprotein Induction at the BloodBrain Barrier of a $\beta$-Amyloidosis Mouse Model with (11)C-Metoclopramide PET. J Nucl Med 2020, 61, 1050-1057, doi:10.2967/jnumed.119.237198.

163. Mossel, P.; Garcia Varela, L.; Arif, W.M.; van der Weijden, C.W.J.; Boersma, H.H.; Willemsen, A.T.M.; Boellaard, R.; Elsinga, P.H.; Borra, R.J.H.; Colabufo, N.A.; et al. Evaluation of P-glycoprotein function at the blood-brain barrier using [(18)F]MC225-PET. Eur J Nucl Med Mol Imaging 2021, doi:10.1007/s00259-021-05419-8.

164. Raaphorst, R.M.; Luurtsema, G.; Schuit, R.C.; Kooijman, E.J.M.; Elsinga, P.H.; Lammertsma, A.A.; Windhorst, A.D. Synthesis and Evaluation of New Fluorine-18 Labeled Verapamil Analogs To Investigate the Function of P-Glycoprotein in the Blood-Brain Barrier. ACS Chem Neurosci 2017, 8, 1925-1936, doi:10.1021/acschemneuro.7b00086.

165. Zoufal, V.; Mairinger, S.; Krohn, M.; Wanek, T.; Filip, T.; Sauberer, M.; Stanek, J.; Kuntner, C.; Pahnke, J.; Langer, O. Measurement of cerebral ABCC1 transport activity in wild-type and APP/PS1-21 mice with positron emission tomography. J Cereb Blood Flow Metab 2020, 40, 954-965, doi:10.1177/0271678x19854541.

166. Wanek, T.; Zoufal, V.; Brackhan, M.; Krohn, M.; Mairinger, S.; Filip, T.; Sauberer, M.; Stanek, J.; Pekar, T.; Pahnke, J.; et al. Brain Distribution of Dual ABCB1/ABCG2 Substrates Is Unaltered in a Beta-Amyloidosis Mouse Model. Int J Mol Sci 2020, 21, doi:10.3390/ijms21218245.

167. García-Varela, L.; Arif, W.M.; Vállez García, D.; Kakiuchi, T.; Ohba, H.; Harada, N.; Tago, T.; Elsinga, P.H.; Tsukada, H.; Colabufo, N.A.; et al. Pharmacokinetic Modeling of $[18 \mathrm{~F}] \mathrm{MC} 225$ for Quantification of the P-Glycoprotein Function at the Blood-Brain Barrier in Non-Human Primates with PET. Molecular Pharmaceutics 2020, 17, 3477-3486, doi:10.1021/acs.molpharmaceut.0c00514.

168. Savolainen, H.; Windhorst, A.D.; Elsinga, P.H.; Cantore, M.; Colabufo, N.A.; Willemsen, A.T.; Luurtsema, G. Evaluation of [(18)F]MC225 as a PET radiotracer for measuring Pglycoprotein function at the blood-brain barrier in rats: Kinetics, metabolism, and selectivity. Journal of cerebral blood flow and metabolism : official journal of the International Society of Cerebral Blood Flow and Metabolism 2017, 37, 1286-1298, doi:10.1177/0271678X16654493.

169. Schmidt, A.M.; Yan, S.D.; Yan, S.F.; Stern, D.M. The biology of the receptor for advanced glycation end products and its ligands. Biochim Biophys Acta 2000, 1498, 99-111, doi:10.1016/s0167-4889(00)00087-2.

170. Yan, S.D.; Chen, X.; Fu, J.; Chen, M.; Zhu, H.; Roher, A.; Slattery, T.; Zhao, L.; Nagashima, M.; Morser, J.; et al. RAGE and amyloid-beta peptide neurotoxicity in Alzheimer's disease. Nature 1996, 382, 685-691, doi:10.1038/382685a0. 
171. Kong, Y.; Hua, F.; Guan, Y.; Zhao, B. RAGE-specific probe 18F -FPS-ZM1 may be a promising biomarker for early detection of Diabetes with Alzheimer's disease. Journal of Nuclear Medicine 2016, 57, 1049.

172. Cary, B.P.; Brooks, A.F.; Fawaz, M.V.; Drake, L.R.; Desmond, T.J.; Sherman, P.; Quesada, C.A.; Scott, P.J. Synthesis and Evaluation of [(18)F]RAGER: A First Generation SmallMolecule PET Radioligand Targeting the Receptor for Advanced Glycation Endproducts. ACS Chem Neurosci 2016, 7, 391-398, doi:10.1021/acschemneuro.5b00319.

173. Drake, L.R.; Brooks, A.F.; Stauff, J.; Sherman, P.S.; Arteaga, J.; Koeppe, R.A.; Reed, A.; Montavon, T.J.; Skaddan, M.B.; Scott, P.J.H. Strategies for PET imaging of the receptor for advanced glycation endproducts (RAGE). J Pharm Anal 2020, 10, 452-465, doi:10.1016/j.jpha.2020.07.009.

174. Konopka, C.J.; Wozniak, M.; Hedhli, J.; Ploska, A.; Schwartz-Duval, A.; Siekierzycka, A.; Pan, D.; Munirathinam, G.; Dobrucki, I.T.; Kalinowski, L.; et al. Multimodal imaging of the receptor for advanced glycation end-products with molecularly targeted nanoparticles. Theranostics 2018, 8, 5012-5024, doi:10.7150/thno.24791.

175. Luzi, F.; Savickas, V.; Taddei, C.; Hader, S.; Singh, N.; Gee, A.D.; Bongarzone, S. Radiolabeling of [(11)C]FPS-ZM1, a receptor for advanced glycation end products-targeting positron emission tomography radiotracer, using a $[(11) \mathrm{C}] \mathrm{CO}(2)$-to- $[(11) \mathrm{C}] \mathrm{CO}$ chemical conversion. Future Med Chem 2020, 12, 511-521, doi:10.4155/fmc-2019-0329.

176. Kreis1, W.C.; Kim, M.J.; Coughlin, J.M.; Henter, I.D.; Owen, D.R.; Innis, R.B. PET imaging of neuroinflammation in neurological disorders. Lancet Neurol 2020, 19, 940-950, doi:10.1016/s1474-4422(20)30346-X.

177. Leng, F.; Edison, P. Neuroinflammation and microglial activation in Alzheimer disease: where do we go from here? Nature Reviews Neurology 2021, 17, 157-172, doi:10.1038/s41582-020-00435-y.

178. Janssen, B.; Mach, R.H. Development of brain PET imaging agents: Strategies for imaging neuroinflammation in Alzheimer's disease. Prog Mol Biol Transl Sci 2019, 165, 371-399, doi:10.1016/bs.pmbts.2019.04.005.

179. Van Camp, N.; Lavisse, S.; Roost, P.; Gubinelli, F.; Hillmer, A.; Boutin, H. TSPO imaging in animal models of brain diseases. Eur J Nucl Med Mol Imaging 2021, doi:10.1007/s00259021-05379-Z.

180. Zhou, R.; Ji, B.; Kong, Y.; Qin, L.; Ren, W.; Guan, Y.; Ni, R. PET Imaging of Neuroinflammation in Alzheimer's Disease. Frontiers in Immunology 2021, 12, 3750.

181. Pascoal, T.A.; Benedet, A.L.; Ashton, N.J.; Kang, M.S.; Therriault, J.; Chamoun, M.; Savard, M.; Lussier, F.Z.; Tissot, C.; Karikari, T.K.; et al. Microglial activation and tau propagate jointly across Braak stages. Nat Med 2021, doi:10.1038/s41591-021-01456-w.

182. Ising, C.; Venegas, C.; Zhang, S.; Scheiblich, H.; Schmidt, S.V.; Vieira-Saecker, A.; Schwartz, S.; Albasset, S.; McManus, R.M.; Tejera, D.; et al. NLRP3 inflammasome activation drives tau pathology. Nature 2019, 575, 669-673, doi:10.1038/s41586-019-1769-z.

183. Heneka, M.T.; Carson, M.J.; El Khoury, J.; Landreth, G.E.; Brosseron, F.; Feinstein, D.L.; Jacobs, A.H.; Wyss-Coray, T.; Vitorica, J.; Ransohoff, R.M.; et al. Neuroinflammation in Alzheimer's disease. Lancet Neurol 2015, 14, 388-405, doi:10.1016/s1474-4422(15)70016-5. 
184. Huang, Y.; Happonen, K.E.; Burrola, P.G.; O'Connor, C.; Hah, N.; Huang, L.; Nimmerjahn, A.; Lemke, G. Microglia use TAM receptors to detect and engulf amyloid $\beta$ plaques. Nat Immunol 2021, 22, 586-594, doi:10.1038/s41590-021-00913-5.

185. Deczkowska, A.; Keren-Shaul, H.; Weiner, A.; Colonna, M.; Schwartz, M.; Amit, I. DiseaseAssociated Microglia: A Universal Immune Sensor of Neurodegeneration. Cell 2018, 173, 1073-1081, doi:https://doi.org/10.1016/j.cell.2018.05.003.

186. Keren-Shaul, H.; Spinrad, A.; Weiner, A.; Matcovitch-Natan, O.; Dvir-Szternfeld, R.; Ulland, T.K.; David, E.; Baruch, K.; Lara-Astaiso, D.; Toth, B.; et al. A Unique Microglia Type Associated with Restricting Development of Alzheimer's Disease. Cell 2017, 169, 1276 1290.e1217, doi:10.1016/j.cell.2017.05.018.

187. Song, W.M.; Colonna, M. The identity and function of microglia in neurodegeneration. Nat Immunol 2018, 19, 1048-1058, doi:10.1038/s41590-018-0212-1.

188. Venneti, S.; Lopresti, B.J.; Wang, G.; Hamilton, R.L.; Mathis, C.A.; Klunk, W.E.; Apte, U.M.; Wiley, C.A. PK11195 labels activated microglia in Alzheimer's disease and in vivo in a mouse model using PET. Neurobiology of Aging 2009, 30, 1217-1226, doi:https://doi.org/10.1016/j.neurobiolaging.2007.11.005.

189. Mirzaei, N.; Tang, S.P.; Ashworth, S.; Coello, C.; Plisson, C.; Passchier, J.; Selvaraj, V.; Tyacke, R.J.; Nutt, D.J.; Sastre, M. In vivo imaging of microglial activation by positron emission tomography with [(11)C]PBR28 in the 5XFAD model of Alzheimer's disease. Glia 2016, 64, 993-1006, doi:10.1002/glia.22978.

190. Maeda, J.; Ji, B.; Irie, T.; Tomiyama, T.; Maruyama, M.; Okauchi, T.; Staufenbiel, M.; Iwata, N.; Ono, M.; Saido, T.C.; et al. Longitudinal, quantitative assessment of amyloid, neuroinflammation, and anti-amyloid treatment in a living mouse model of Alzheimer's disease enabled by positron emission tomography. The Journal of neuroscience : the official journal of the Society for Neuroscience 2007, 27, 10957-10968, doi:10.1523/JNEUROSCI.0673-07.2007.

191. Ikawa, M.; Lohith, T.G.; Shrestha, S.; Telu, S.; Zoghbi, S.S.; Castellano, S.; Taliani, S.; Da Settimo, F.; Fujita, M.; Pike, V.W.; et al. 11C-ER176, a Radioligand for 18-kDa Translocator Protein, Has Adequate Sensitivity to Robustly Image All Three Affinity Genotypes in Human Brain. J Nucl Med 2017, 58, 320-325, doi:10.2967/jnumed.116.178996.

192. Sacher, C.; Blume, T.; Beyer, L.; Peters, F.; Eckenweber, F.; Sgobio, C.; Deussing, M.; Albert, N.L.; Unterrainer, M.; Lindner, S.; et al. Longitudinal PET Monitoring of Amyloidosis and Microglial Activation in a Second-Generation Amyloid- $\beta$ Mouse Model. $J$ Nucl Med 2019, 60, 1787-1793, doi:10.2967/jnumed.119.227322.

193. Wright, A.L.; Zinn, R.; Hohensinn, B.; Konen, L.M.; Beynon, S.B.; Tan, R.P.; Clark, I.A.; Abdipranoto, A.; Vissel, B. Neuroinflammation and Neuronal Loss Precede A $\beta$ Plaque Deposition in the hAPP-J20 Mouse Model of Alzheimer's Disease. PLOS ONE 2013, 8, e59586, doi:10.1371/journal.pone.0059586.

194. López-Picón, F.R.; Snellman, A.; Eskola, O.; Helin, S.; Solin, O.; Haaparanta-Solin, M.; Rinne, J.O. Neuroinflammation Appears Early on PET Imaging and Then Plateaus in a Mouse Model of Alzheimer Disease. Journal of Nuclear Medicine 2018, 59, 509, doi:10.2967/jnumed.117.197608.

195. Brendel, M.; Kleinberger, G.; Probst, F.; Jaworska, A.; Overhoff, F.; Blume, T.; Albert, N.L.; Carlsen, J.; Lindner, S.; Gildehaus, F.J.; et al. Increase of TREM2 during Aging of an 
Alzheimer's Disease Mouse Model Is Paralleled by Microglial Activation and Amyloidosis. Frontiers in Aging Neuroscience 2017, 9, 8.

196. Focke, C.; Blume, T.; Zott, B.; Shi, Y.; Deussing, M.; Peters, F.; Schmidt, C.; Kleinberger, G.; Lindner, S.; Gildehaus, F.J.; et al. Early and Longitudinal Microglial Activation but Not Amyloid Accumulation Predicts Cognitive Outcome in PS2APP Mice. J Nucl Med 2019, 60, 548-554, doi:10.2967/jnumed.118.217703.

197. Biechele, G.; Wind, K.; Blume, T.; Sacher, C.; Beyer, L.; Eckenweber, F.; Franzmeier, N.; Ewers, M.; Zott, B.; Lindner, S.; et al. Microglial activation in the right amygdala-entorhinalhippocampal complex is associated with preserved spatial learning in App(NL-G-F) mice. Neuroimage 2021, 230, 117707, doi:10.1016/j.neuroimage.2020.117707.

198. Ji, B.; Ono, M.; Yamasaki, T.; Fujinaga, M.; Zhang, M.R.; Seki, C.; Aoki, I.; Kito, S.; Sawada, M.; Suhara, T.; et al. Detection of Alzheimer's disease-related neuroinflammation by a PET ligand selective for glial versus vascular translocator protein. J Cereb Blood Flow Metab 2021, 271678x21992457, doi:10.1177/0271678x21992457.

199. Beaino, W.; Janssen, B.; Vugts, D.J.; de Vries, H.E.; Windhorst, A.D. Toward PET imaging of the dynamic phenotypes of microglia. Clin Exp Immunol 2021, doi:10.1111/cei.13649.

200. Ni, R.; Müller Herde, A.; Haider, A.; Keller, C.; Louloudis, G.; Vaas, M.; Schibli, R.; Ametamey, S.M.; Klohs, J.; Mu, L. In vivo Imaging of Cannabinoid Type 2 Receptors: Functional and Structural Alterations in Mouse Model of Cerebral Ischemia by PET and MRI. Molecular Imaging and Biology 2021, doi:10.1007/s11307-021-01655-4.

201. Hagens, M.H.J.; Golla, S.S.V.; Janssen, B.; Vugts, D.J.; Beaino, W.; Windhorst, A.D.; O’Brien-Brown, J.; Kassiou, M.; Schuit, R.C.; Schwarte, L.A.; et al. The P2X7 receptor tracer [11C]SMW139 as an in vivo marker of neuroinflammation in multiple sclerosis: a first-in man study. European Journal of Nuclear Medicine and Molecular Imaging 2020, 47, 379389, doi:10.1007/s00259-019-04550-X.

202. Janssen, B.; Vugts, D.J.; Wilkinson, S.M.; Ory, D.; Chalon, S.; Hoozemans, J.J.M.; Schuit, R.C.; Beaino, W.; Kooijman, E.J.M.; van den Hoek, J.; et al. Identification of the allosteric P2X7 receptor antagonist [11C]SMW139 as a PET tracer of microglial activation. Scientific Reports 2018, 8, 6580, doi:10.1038/s41598-018-24814-0.

203. Maeda, J.; Minamihisamatsu, T.; Shimojo, M.; Zhou, X.; Ono, M.; Matsuba, Y.; Ji, B.; Ishii, H.; Ogawa, M.; Akatsu, H.; et al. Distinct microglial response against Alzheimer's amyloid and tau pathologies characterized by P2Y12 receptor. Brain Commun 2021, 3, fcab011, doi:10.1093/braincomms/fcab011.

204. Horti, A.G.; Naik, R.; Foss, C.A.; Minn, I.; Misheneva, V.; Du, Y.; Wang, Y.; Mathews, W.B.; Wu, Y.; Hall, A.; et al. PET imaging of microglia by targeting macrophage colonystimulating factor 1 receptor (CSF1R). Proc Natl Acad Sci U S A 2019, 116, 1686-1691, doi:10.1073/pnas.1812155116.

205. Zhou, X.; Ji, B.; Seki, C.; Nagai, Y.; Minamimoto, T.; Fujinaga, M.; Zhang, M.R.; Saito, T.; Saido, T.C.; Suhara, T.; et al. PET imaging of colony-stimulating factor 1 receptor: A headto-head comparison of a novel radioligand, (11)C-GW2580, and (11)C-CPPC, in mouse models of acute and chronic neuroinflammation and a rhesus monkey. J Cereb Blood Flow Metab 2021, 271678x211004146, doi:10.1177/0271678x211004146.

206. Shukuri, M.; Mawatari, A.; Ohno, M.; Suzuki, M.; Doi, H.; Watanabe, Y.; Onoe, H. Detection of Cyclooxygenase-1 in Activated Microglia During Amyloid Plaque Progression: 
PET Studies in Alzheimer's Disease Model Mice. J Nucl Med 2016, 57, 291-296, doi:10.2967/jnumed.115.166116.

207. Meier, S.R.; Sehlin, D.; Hultqvist, G.; Syvänen, S. Pinpointing Brain TREM2 Levels in Two Mouse Models of Alzheimer's Disease. Mol Imaging Biol 2021, doi:10.1007/s11307-02101591-3.

208. Torres, J.B.; Andreozzi, E.M.; Dunn, J.T.; Siddique, M.; Szanda, I.; Howlett, D.R.; Sunassee, K.; Blower, P.J. PET Imaging of Copper Trafficking in a Mouse Model of Alzheimer Disease. J Nucl Med 2016, 57, 109-114, doi:10.2967/jnumed.115.162370.

209. Hou, C.; Hsieh, C.-J.; Li, S.; Lee, H.; Graham, T.J.; Xu, K.; Weng, C.-C.; Doot, R.K.; Chu, W.; Chakraborty, S.K.; et al. Development of a Positron Emission Tomography Radiotracer for Imaging Elevated Levels of Superoxide in Neuroinflammation. ACS chemical neuroscience 2018, 9, 578-586, doi:10.1021/acschemneuro.7b00385.

210. Schützmann, M.P.; Hasecke, F.; Bachmann, S.; Zielinski, M.; Hänsch, S.; Schröder, G.F.; Zempel, H.; Hoyer, W. Endo-lysosomal A $\beta$ concentration and $\mathrm{pH}$ trigger formation of A $\beta$ oligomers that potently induce Tau missorting. Nature Communications 2021, 12, 4634, doi:10.1038/s41467-021-24900-4.

211. Kumar, J.S.D.; Solingapuram Sai, K.K.; Prabhakaran, J.; Oufkir, H.R.; Ramanathan, G.; Whitlow, C.T.; Dileep, H.; Mintz, A.; Mann, J.J. Radiosynthesis and in Vivo Evaluation of [(11)C]MPC-6827, the First Brain Penetrant Microtubule PET Ligand. J Med Chem 2018, 61, 2118-2123, doi:10.1021/acs.jmedchem.8b00028.

212. Solingapuram Sai, K.K.; Prabhakaran, J.; Ramanathan, G.; Rideout, S.; Whitlow, C.; Mintz, A.; Mann, J.J.; Kumar, J.S.D. Radiosynthesis and Evaluation of [11C]HD-800, a High Affinity Brain Penetrant PET Tracer for Imaging Microtubules. ACS Medicinal Chemistry Letters 2018, 9, 452-456, doi:10.1021/acsmedchemlett.8b00060.

213. Sai, K.S.; Damuka, N.; Mintz, A.; Whitlow, C.T.; Craft, S.; Macauley-Rambach, S. [11C]MPC-6827, a microtubule-based PET imaging tracer: A potential early imaging biomarker for AD and other ADRDs. Alzheimer's \& Dementia 2020, 16, e037790, doi:https://doi.org/10.1002/alz.037790.

214. Baum, E.; Cai, Z.; Bois, F.; Holden, D.; Lin, S.F.; Lara-Jaime, T.; Kapinos, M.; Chen, Y.; Deuther-Conrad, W.; Fischer, S.; et al. PET Imaging Evaluation of Four $\sigma(1)$ Radiotracers in Nonhuman Primates. J Nucl Med 2017, 58, 982-988, doi:10.2967/jnumed.116.188052.

215. Lepelletier, F.-X.; Vandesquille, M.; Asselin, M.-C.; Prenant, C.; Robinson, A.C.; Mann, D.M.A.; Green, M.; Barnett, E.; Banister, S.D.; Mottinelli, M.; et al. Evaluation of (18)FIAM6067 as a sigma-1 receptor PET tracer for neurodegeneration in vivo in rodents and in human tissue. Theranostics 2020, 10, 7938-7955, doi:10.7150/thno.47585.

216. Lan, Y.; Bai, P.; Chen, Z.; Neelamegam, R.; Placzek, M.S.; Wang, H.; Fiedler, S.A.; Yang, J.; Yuan, G.; Qu, X.; et al. Novel radioligands for imaging sigma-1 receptor in brain using positron emission tomography (PET). Acta Pharmaceutica Sinica B 2019, 9, 1204-1215, doi:https://doi.org/10.1016/j.apsb.2019.07.002.

217. Satoru, Y.; Yurika, I.; Shunsuke, I.; Takeharu, K.; Hiroyuki, O.; Shingo, N.; Masakatsu, K.; Hideo, T.; Kohji, S.; Yasuomi, O. Research Square 2021, doi:10.21203/rs.3.rs-27076/v1.

218. Giglio, J.; Fernandez, S.; Martinez, A.; Zeni, M.; Reyes, L.; Rey, A.; Cerecetto, H. Glycogen Synthase Kinase-3 Maleimide Inhibitors As Potential PET-Tracers for Imaging Alzheimer's 
Disease: (11)C-Synthesis and In Vivo Proof of Concept. J Med Chem 2021, doi:10.1021/acs.jmedchem.1c00769.

219. Knight, A.C.; Varlow, C.; Tong, J.; Vasdev, N. In Vitro and In Vivo Evaluation of GSK-3 Radioligands in Alzheimer's Disease: Preliminary Evidence of Sex Differences. ACS Pharmacol Transl Sci 2021, 4, 1287-1294, doi:10.1021/acsptsci.1c00132.

220. Escartin, C.; Galea, E.; Lakatos, A.; O'Callaghan, J.P.; Petzold, G.C.; Serrano-Pozo, A.; Steinhäuser, C.; Volterra, A.; Carmignoto, G.; Agarwal, A.; et al. Reactive astrocyte nomenclature, definitions, and future directions. Nat Neurosci 2021, 24, 312-325, doi:10.1038/s41593-020-00783-4.

221. Joshi, A.U.; Minhas, P.S.; Liddelow, S.A.; Haileselassie, B.; Andreasson, K.I.; Dorn, G.W., 2nd; Mochly-Rosen, D. Fragmented mitochondria released from microglia trigger A1 astrocytic response and propagate inflammatory neurodegeneration. Nat Neurosci 2019, 22, 1635-1648, doi:10.1038/s41593-019-0486-0.

222. Castellani, G.; Schwartz, M. Immunological Features of Non-neuronal Brain Cells: Implications for Alzheimer's Disease Immunotherapy. Trends Immunol 2020, 41, 794-804, doi:10.1016/j.it.2020.07.005.

223. McAlpine, C.S.; Park, J.; Griciuc, A.; Kim, E.; Choi, S.H.; Iwamoto, Y.; Kiss, M.G.; Christie, K.A.; Vinegoni, C.; Poller, W.C.; et al. Astrocytic interleukin-3 programs microglia and limits Alzheimer's disease. Nature 2021, doi:10.1038/s41586-021-03734-6.

224. Damisah, E.C.; Hill, R.A.; Rai, A.; Chen, F.; Rothlin, C.V.; Ghosh, S.; Grutzendler, J. Astrocytes and microglia play orchestrated roles and respect phagocytic territories during neuronal corpse removal in vivo. Sci Adv 2020, 6, eaba3239, doi:10.1126/sciadv.aba3239.

225. Habib, N.; McCabe, C.; Medina, S.; Varshavsky, M.; Kitsberg, D.; Dvir-Szternfeld, R.; Green, G.; Dionne, D.; Nguyen, L.; Marshall, J.L.; et al. Disease-associated astrocytes in Alzheimer's disease and aging. Nat Neurosci 2020, 23, 701-706, doi:10.1038/s41593-0200624-8.

226. Olsen, M.; Aguilar, X.; Sehlin, D.; Fang, X.T.; Antoni, G.; Erlandsson, A.; Syvänen, S. Astroglial Responses to Amyloid-Beta Progression in a Mouse Model of Alzheimer's Disease. Mol Imaging Biol 2018, 20, 605-614, doi:10.1007/s1 1307-017-1153-z.

227. Harada, R.; Hayakawa, Y.; Ezura, M.; Lerdsirisuk, P.; Du, Y.; Ishikawa, Y.; Iwata, R.; Shidahara, M.; Ishiki, A.; Kikuchi, A.; et al. (18)F-SMBT-1: A Selective and Reversible PET Tracer for Monoamine Oxidase-B Imaging. J Nucl Med 2021, 62, 253-258, doi:10.2967/jnumed.120.244400.

228. Alzghool, O.M.; Rokka, J.; López-Picón, F.R.; Snellman, A.; Helin, J.S.; Okamura, N.; Solin, O.; Rinne, J.O.; Haaparanta-Solin, M. (S)-[(18)F]THK5117 brain uptake is associated with $\mathrm{A} \beta$ plaques and MAO-B enzyme in a mouse model of Alzheimer's disease. Neuropharmacology 2021, 196, 108676, doi:10.1016/j.neuropharm.2021.108676.

229. Dukić-Stefanović, S.; Hang Lai, T.; Toussaint, M.; Clauß, O.; Jevtić, II; Penjišević, J.Z.; Andrić, D.; Ludwig, F.A.; Gündel, D.; Deuther-Conrad, W.; et al. In vitro and in vivo evaluation of fluorinated indanone derivatives as potential positron emission tomography agents for the imaging of monoamine oxidase B in the brain. Bioorg Med Chem Lett 2021, 48, 128254, doi:10.1016/j.bmcl.2021.128254. 
230. Kumar, A.; Koistinen, N.A.; Malarte, M.-L.; Nennesmo, I.; Ingelsson, M.; Ghetti, B.; Lemoine, L.; Nordberg, A. Astroglial tracer BU99008 detects multiple binding sites in Alzheimer's disease brain. Molecular Psychiatry 2021, doi:10.1038/s41380-021-01101-5.

231. Livingston, N.R.; Calsolaro, V.; Hinz, R.; Nowell, J.; Raza, S.; Gentleman, S.; Tyacke, R.J.; Myers, J.; Venkataraman, A.V.; Perneczky, R.; et al. Relationship between astrocyte reactivity, using novel $<$ sup $>11</$ sup $>$ C-BU99008 PET, and glucose metabolism, grey matter volume and amyloid load in cognitively impaired individuals. medRxiv 2021, 2021.2008.2010.21261690, doi:10.1101/2021.08.10.21261690.

232. Calsolaro, V.; Matthews, P.M.; Donat, C.K.; Livingston, N.R.; Femminella, G.D.; Guedes, S.S.; Myers, J.; Fan, Z.; Tyacke, R.J.; Venkataraman, A.V.; et al. Astrocyte reactivity with late-onset cognitive impairment assessed in vivo using 11C-BU99008 PET and its relationship with amyloid load. Molecular Psychiatry 2021, doi:10.1038/s41380-021-01193$\mathrm{Z}$.

233. Ashe, K.H.; Zahs, K.R. Probing the biology of Alzheimer's disease in mice. Neuron 2010, 66, 631-645, doi:10.1016/j.neuron.2010.04.031.

234. Joel, Z.; Izquierdo, P.; Salih, D.A.; Richardson, J.C.; Cummings, D.M.; Edwards, F.A. Improving Mouse Models for Dementia. Are All the Effects in Tau Mouse Models Due to Overexpression? Cold Spring Harb Symp Quant Biol 2018, 83, 151-161, doi:10.1101/sqb.2018.83.037531.

235. Neuner, S.M.; Heuer, S.E.; Huentelman, M.J.; O'Connell, K.M.S.; Kaczorowski, C.C. Harnessing Genetic Complexity to Enhance Translatability of Alzheimer's Disease Mouse Models: A Path toward Precision Medicine. Neuron 2019, 101, 399-411.e395, doi:10.1016/j.neuron.2018.11.040.

236. Hodge, R.D.; Bakken, T.E.; Miller, J.A.; Smith, K.A.; Barkan, E.R.; Graybuck, L.T.; Close, J.L.; Long, B.; Johansen, N.; Penn, O.; et al. Conserved cell types with divergent features in human versus mouse cortex. Nature 2019, 573, 61-68, doi:10.1038/s41586-019-1506-7.

237. Rosen, R.F.; Tomidokoro, Y.; Farberg, A.S.; Dooyema, J.; Ciliax, B.; Preuss, T.M.; Neubert, T.A.; Ghiso, J.A.; LeVine, H., 3rd; Walker, L.C. Comparative pathobiology of $\beta$-amyloid and the unique susceptibility of humans to Alzheimer's disease. Neurobiology of aging 2016, 44, 185-196, doi:10.1016/j.neurobiolaging.2016.04.019.

238. Vitek, M.P.; Araujo, J.A.; Fossel, M.; Greenberg, B.D.; Howell, G.R.; Rizzo, S.J.S.; Seyfried, N.T.; Tenner, A.J.; Territo, P.R.; Windisch, M.; et al. Translational animal models for Alzheimer's disease: An Alzheimer's Association Business Consortium Think Tank. Alzheimer's \& Dementia: Translational Research \& Clinical Interventions 2020, 6, e12114, doi:https://doi.org/10.1002/trc2.12114.

239. Oblak, A.L.; Forner, S.; Territo, P.R.; Sasner, M.; Carter, G.W.; Howell, G.R.; Sukoff-Rizzo, S.J.; Logsdon, B.A.; Mangravite, L.M.; Mortazavi, A.; et al. Model organism development and evaluation for late-onset Alzheimer's disease: MODEL-AD. Alzheimers Dement $(N Y)$ 2020, 6, e12110, doi:10.1002/trc2.12110.

240. Su, J.H.; Zheng, P.; Kinrot, S.S.; Bintu, B.; Zhuang, X. Genome-Scale Imaging of the 3D Organization and Transcriptional Activity of Chromatin. Cell 2020, 182, 1641-1659.e1626, doi:10.1016/j.cell.2020.07.032. 
241. Martins, D.; Giacomel, A.; Williams, S.; Turkheimer, F.; Dipasquale, O.; Veronese, M. Imaging transcriptomics: Convergent cellular, transcriptomic, and molecular neuroimaging signatures in the healthy adult human brain; 2021.

242. Girgenti, M.J.; Wang, J.; Ji, D.; Cruz, D.A.; Alvarez, V.E.; Benedek, D.; Brady, C.; Davis, D.A.; Holtzheimer, P.E.; Keane, T.M.; et al. Transcriptomic organization of the human brain in post-traumatic stress disorder. Nature Neuroscience 2021, 24, 24-33, doi:10.1038/s41593020-00748-7.

243. Preuss, C.; Pandey, R.; Piazza, E.; Fine, A.; Uyar, A.; Perumal, T.; Garceau, D.; Kotredes, K.P.; Williams, H.; Mangravite, L.M.; et al. A novel systems biology approach to evaluate mouse models of late-onset Alzheimer's disease. Mol Neurodegener 2020, 15, 67, doi:10.1186/s13024-020-00412-5.

244. Rodriguez-Vieitez, E.; Ni, R.Q.; Gulyas, B.; Toth, M.; Haggkvist, J.; Halldin, C.; Voytenko, L.; Marutle, A.; Nordberg, A. Astrocytosis precedes amyloid plaque deposition in Alzheimer APPswe transgenic mouse brain: a correlative positron emission tomography and in vitro imaging study. European Journal of Nuclear Medicine and Molecular Imaging 2015, 42, 1119-1132, doi:10.1007/s00259-015-3047-0.

245. Toyama, H.; Ye, D.; Ichise, M.; Liow, J.S.; Cai, L.; Jacobowitz, D.; Musachio, J.L.; Hong, J.; Crescenzo, M.; Tipre, D.; et al. PET imaging of brain with the beta-amyloid probe, [11C]6OH-BTA-1, in a transgenic mouse model of Alzheimer's disease. Eur J Nucl Med Mol Imaging 2005, 32, 593-600, doi:10.1007/s00259-005-1780-5.

246. Klunk, W.E.; Lopresti, B.J.; Ikonomovic, M.D.; Lefterov, I.M.; Koldamova, R.P.; Abrahamson, E.E.; Debnath, M.L.; Holt, D.P.; Huang, G.F.; Shao, L.; et al. Binding of the positron emission tomography tracer Pittsburgh compound-B reflects the amount of amyloidbeta in Alzheimer's disease brain but not in transgenic mouse brain. The Journal of neuroscience : the official journal of the Society for Neuroscience 2005, 25, 10598-10606, doi:10.1523/JNEUROSCI.2990-05.2005.

247. Manook, A.; Yousefi, B.H.; Willuweit, A.; Platzer, S.; Reder, S.; Voss, A.; Huisman, M.; Settles, M.; Neff, F.; Velden, J.; et al. Small-animal PET imaging of amyloid-beta plaques with [11C]PiB and its multi-modal validation in an APP/PS1 mouse model of Alzheimer's disease. PLoS One 2012, 7, e31310, doi:10.1371/journal.pone.0031310.

248. von Reutern, B.; Grünecker, B.; Yousefi, B.H.; Henriksen, G.; Czisch, M.; Drzezga, A. Voxel-based analysis of amyloid-burden measured with [(11)C]PiB PET in a double transgenic mouse model of Alzheimer's disease. Mol Imaging Biol 2013, 15, 576-584, doi:10.1007/s11307-013-0625-z.

249. Chiquita, S.; Ribeiro, M.; Castelhano, J.; Oliveira, F.; Sereno, J.; Batista, M.; Abrunhosa, A.; Rodrigues-Neves, A.C.; Carecho, R.; Baptista, F.; et al. A longitudinal multimodal in vivo molecular imaging study of the $3 \times$ Tg-AD mouse model shows progressive early hippocampal and taurine loss. Hum Mol Genet 2019, 28, 2174-2188, doi:10.1093/hmg/ddz045.

250. Waldron, A.M.; Wyffels, L.; Verhaeghe, J.; Richardson, J.C.; Schmidt, M.; Stroobants, S.; Langlois, X.; Staelens, S. Longitudinal Characterization of [18F]-FDG and [18F]-AV45 Uptake in the Double Transgenic TASTPM Mouse Model. J Alzheimers Dis 2017, 55, 15371548, doi:10.3233/jad-160760. 
251. Poisnel, G.; Dhilly, M.; Moustié, O.; Delamare, J.; Abbas, A.; Guilloteau, D.; Barré, L. PET imaging with [18F]AV-45 in an APP/PS1-21 murine model of amyloid plaque deposition. Neurobiol Aging 2012, 33, 2561-2571, doi:10.1016/j.neurobiolaging.2011.12.024.

252. Sacher, C.; Blume, T.; Beyer, L.; Biechele, G.; Sauerbeck, J.; Eckenweber, F.; Deussing, M.; Focke, C.; Parhizkar, S.; Lindner, S.; et al. Asymmetry of fibrillar plaque burden in amyloid mouse models. J Nucl Med 2020, doi:10.2967/jnumed.120.242750.

253. Rominger, A.; Brendel, M.; Burgold, S.; Keppler, K.; Baumann, K.; Xiong, G.; Mille, E.; Gildehaus, F.J.; Carlsen, J.; Schlichtiger, J.; et al. Longitudinal assessment of cerebral $\beta$ amyloid deposition in mice overexpressing Swedish mutant $\beta$-amyloid precursor protein using 18F-florbetaben PET. J Nucl Med 2013, 54, 1127-1134, doi:10.2967/jnumed.112.114660.

254. Biechele, G.; Franzmeier, N.; Blume, T.; Ewers, M.; Luque, J.M.; Eckenweber, F.; Sacher, C.; Beyer, L.; Ruch-Rubinstein, F.; Lindner, S.; et al. Glial activation is moderated by sex in response to amyloidosis but not to tau pathology in mouse models of neurodegenerative diseases. J Neuroinflammation 2020, 17, 374, doi:10.1186/s12974-020-02046-2.

255. Blume, T.; Focke, C.; Peters, F.; Deussing, M.; Albert, N.L.; Lindner, S.; Gildehaus, F.-J.; von Ungern-Sternberg, B.; Ozmen, L.; Baumann, K.; et al. Microglial response to increasing amyloid load saturates with aging: a longitudinal dual tracer in vivo $\mu$ PET-study. Journal of Neuroinflammation 2018, 15, 307, doi:10.1186/s12974-018-1347-6.

256. Franke, T.N.; Irwin, C.; Bayer, T.A.; Brenner, W.; Beindorff, N.; Bouter, C.; Bouter, Y. In vivo Imaging With 18F-FDG- and 18F-Florbetaben-PET/MRI Detects Pathological Changes in the Brain of the Commonly Used 5XFAD Mouse Model of Alzheimer's Disease. Frontiers in Medicine 2020, 7, 529.

257. Johnson, A.E.; Jeppsson, F.; Sandell, J.; Wensbo, D.; Neelissen, J.A.; Juréus, A.; Ström, P.; Norman, H.; Farde, L.; Svensson, S.P. AZD2184: a radioligand for sensitive detection of beta-amyloid deposits. $J$ Neurochem 2009, 108, 1177-1186, doi:10.1111/j.14714159.2008.05861.x.

258. Kudo, Y.; Okamura, N.; Furumoto, S.; Tashiro, M.; Furukawa, K.; Maruyama, M.; Itoh, M.; Iwata, R.; Yanai, K.; Arai, H. 2-(2-[2-Dimethylaminothiazol-5-yl]ethenyl)-6- (2[fluoro]ethoxy)benzoxazole: a novel PET agent for in vivo detection of dense amyloid plaques in Alzheimer's disease patients. J Nucl Med 2007, 48, 553-561, doi:10.2967/jnumed.106.037556.

259. Furumoto, S.; Okamura, N.; Furukawa, K.; Tashiro, M.; Ishikawa, Y.; Sugi, K.; Tomita, N.; Waragai, M.; Harada, R.; Tago, T.; et al. A 18F-Labeled BF-227 Derivative as a Potential Radioligand for Imaging Dense Amyloid Plaques by Positron Emission Tomography. Molecular Imaging and Biology 2013, 15, 497-506, doi:10.1007/s11307-012-0608-5.

260. Sundaram, G.S.M.; Dhavale, D.D.; Prior, J.L.; Yan, P.; Cirrito, J.; Rath, N.P.; Laforest, R.; Cairns, N.J.; Lee, J.-M.; Kotzbauer, P.T.; et al. Fluselenamyl: A Novel Benzoselenazole Derivative for PET Detection of Amyloid Plaques $(\mathrm{A} \beta)$ in Alzheimer's Disease. Scientific Reports 2016, 6, 35636, doi:10.1038/srep35636.

261. Tournier, B.B.; Tsartsalis, S.; Ceyzériat, K.; Fraser, B.H.; Grégoire, M.C.; Kövari, E.; Millet, P. Astrocytic TSPO Upregulation Appears Before Microglial TSPO in Alzheimer's Disease. $J$ Alzheimers Dis 2020, 77, 1043-1056, doi:10.3233/jad-200136. 
262. Chen, C.J.; Bando, K.; Ashino, H.; Taguchi, K.; Shiraishi, H.; Shima, K.; Fujimoto, O.; Kitamura, C.; Matsushima, S.; Uchida, K.; et al. In vivo SPECT imaging of amyloid- $\beta$ deposition with radioiodinated imidazo[1,2-a]pyridine derivative DRM106 in a mouse model of Alzheimer's disease. J Nucl Med 2015, 56, 120-126, doi:10.2967/jnumed.114.146944.

263. Nicholson, R.M.; Kusne, Y.; Nowak, L.A.; LaFerla, F.M.; Reiman, E.M.; Valla, J. Regional cerebral glucose uptake in the 3xTG model of Alzheimer's disease highlights common regional vulnerability across AD mouse models. Brain Res 2010, 1347, 179-185, doi:10.1016/j.brainres.2010.05.084.

264. Sancheti, H.; Akopian, G.; Yin, F.; Brinton, R.D.; Walsh, J.P.; Cadenas, E. Age-dependent modulation of synaptic plasticity and insulin mimetic effect of lipoic acid on a mouse model of Alzheimer's disease. PLoS One 2013, 8, e69830, doi:10.1371/journal.pone.0069830.

265. Luo, F.; Rustay, N.R.; Ebert, U.; Hradil, V.P.; Cole, T.B.; Llano, D.A.; Mudd, S.R.; Zhang, Y.; Fox, G.B.; Day, M. Characterization of 7- and 19-month-old Tg2576 mice using multimodal in vivo imaging: limitations as a translatable model of Alzheimer's disease. Neurobiol Aging 2012, 33, 933-944, doi:10.1016/j.neurobiolaging.2010.08.005.

266. Lourenço, C.F.; Ledo, A.; Barbosa, R.M.; Laranjinha, J. Neurovascular uncoupling in the triple transgenic model of Alzheimer's disease: Impaired cerebral blood flow response to neuronal-derived nitric oxide signaling. Experimental Neurology 2017, 291, 36-43, doi:https://doi.org/10.1016/j.expneurol.2017.01.013.

267. Liu, Y.; Xu, Y.; Li, M.; Pan, D.; Li, Y.; Wang, Y.; Wang, L.; Wu, Q.; Yang, M. Multi-target PET evaluation in APP/PS1/tau mouse model of Alzheimer's disease. Neurosci Lett 2020, 728, 134938, doi:10.1016/j.neulet.2020.134938.

268. Xu, A.; Zeng, Q.; Tang, Y.; Wang, X.; Yuan, X.; Zhou, Y.; Li, Z. Electroacupuncture Protects Cognition by Regulating Tau Phosphorylation and Glucose Metabolism via the AKT/GSK3 $\beta$ Signaling Pathway in Alzheimer's Disease Model Mice. Front Neurosci 2020, 14, 585476, doi:10.3389/fnins.2020.585476.

269. Poisnel, G.; Hérard, A.S.; El Tannir El Tayara, N.; Bourrin, E.; Volk, A.; Kober, F.; Delatour, B.; Delzescaux, T.; Debeir, T.; Rooney, T.; et al. Increased regional cerebral glucose uptake in an APP/PS1 model of Alzheimer's disease. Neurobiol Aging 2012, 33, 1995-2005, doi:10.1016/j.neurobiolaging.2011.09.026.

270. Stojakovic, A.; Trushin, S.; Sheu, A.; Khalili, L.; Chang, S.Y.; Li, X.; Christensen, T.; Salisbury, J.L.; Geroux, R.E.; Gateno, B.; et al. Partial inhibition of mitochondrial complex I ameliorates Alzheimer's disease pathology and cognition in APP/PS1 female mice. Commun Biol 2021, 4, 61, doi:10.1038/s42003-020-01584-y.

271. Wagner, J.M.; Sichler, M.E.; Schleicher, E.M.; Franke, T.N.; Irwin, C.; Löw, M.J.; Beindorff, N.; Bouter, C.; Bayer, T.A.; Bouter, Y. Analysis of Motor Function in the Tg4-42 Mouse Model of Alzheimer's Disease. Frontiers in Behavioral Neuroscience 2019, 13, 107.

272. Macdonald, I.R.; DeBay, D.R.; Reid, G.A.; O'Leary, T.P.; Jollymore, C.T.; Mawko, G.; Burrell, S.; Martin, E.; Bowen, C.V.; Brown, R.E.; et al. Early detection of cerebral glucose uptake changes in the 5XFAD mouse. Curr Alzheimer Res 2014, 11, 450-460, doi:10.2174/1567205011666140505111354.

273. Choi, H.; Choi, Y.; Lee, E.J.; Kim, H.; Lee, Y.; Kwon, S.; Hwang, D.W.; Lee, D.S. Hippocampal glucose uptake as a surrogate of metabolic change of microglia in Alzheimer's disease. J Neuroinflammation 2021, 18, 190, doi:10.1186/s12974-021-02244-6. 
274. Teng, E.; Kepe, V.; Frautschy, S.A.; Liu, J.; Satyamurthy, N.; Yang, F.; Chen, P.P.; Cole, G.B.; Jones, M.R.; Huang, S.C.; et al. [F-18]FDDNP microPET imaging correlates with brain $\mathrm{A} \beta$ burden in a transgenic rat model of Alzheimer disease: effects of aging, in vivo blockade, and anti-A $\beta$ antibody treatment. Neurobiol Dis 2011, 43, 565-575, doi:10.1016/j.nbd.2011.05.003.

275. Winkeler, A.; Waerzeggers, Y.; Klose, A.; Monfared, P.; Thomas, A.V.; Schubert, M.; Heneka, M.T.; Jacobs, A.H. Imaging noradrenergic influence on amyloid pathology in mouse models of Alzheimer's disease. Eur J Nucl Med Mol Imaging 2008, 35 Suppl 1, S107-113, doi:10.1007/s00259-007-0710-0.

276. Deleye, S.; Waldron, A.M.; Richardson, J.C.; Schmidt, M.; Langlois, X.; Stroobants, S.; Staelens, S. The Effects of Physiological and Methodological Determinants on 18F-FDG Mouse Brain Imaging Exemplified in a Double Transgenic Alzheimer Model. Mol Imaging 2016, 15, doi:10.1177/1536012115624919.

277. Son, Y.; Jeong, Y.J.; Shin, N.-R.; Oh, S.J.; Nam, K.R.; Choi, H.-D.; Choi, J.Y.; Lee, H.-J. Inhibition of Colony-Stimulating Factor 1 Receptor by PLX3397 Prevents Amyloid Beta Pathology and Rescues Dopaminergic Signaling in Aging 5xFAD Mice. International Journal of Molecular Sciences 2020, 21, doi:10.3390/ijms21155553.

278. Chen, Y.A.; Lu, C.H.; Ke, C.C.; Chiu, S.J.; Chang, C.W.; Yang, B.H.; Gelovani, J.G.; Liu, R.S. Evaluation of Class IIa Histone Deacetylases Expression and In Vivo Epigenetic Imaging in a Transgenic Mouse Model of Alzheimer's Disease. Int J Mol Sci 2021, 22, doi:10.3390/ijms22168633.

279. Terada, T.; Therriault, J.; Kang, M.S.P.; Savard, M.; Pascoal, T.A.; Lussier, F.; Tissot, C.; Wang, Y.-T.; Benedet, A.; Matsudaira, T.; et al. Mitochondrial complex I abnormalities is associated with tau and clinical symptoms in mild Alzheimer's disease. Molecular Neurodegeneration 2021, 16, 28, doi:10.1186/s13024-021-00448-1.

280. Bernard-Gauthier, V.; Mossine, A.V.; Knight, A.; Patnaik, D.; Zhao, W.N.; Cheng, C.; Krishnan, H.S.; Xuan, L.L.; Chindavong, P.S.; Reis, S.A.; et al. Structural Basis for Achieving GSK-3 $\beta$ Inhibition with High Potency, Selectivity, and Brain Exposure for Positron Emission Tomography Imaging and Drug Discovery. $J$ Med Chem 2019, 62, 96009617, doi:10.1021/acs.jmedchem.9b01030. 


\section{Figure legends}

Figure 1. Imaging of amyloid-beta accumulation, translocator protein and cerebral glucose metabolism in amyloidosis animal models of Alzheimer's disease (a-c) PET images and quantification of $\left[{ }^{11} \mathrm{C}\right] \mathrm{PiB}\left(40-60 \mathrm{~min}\right.$ after injection) and $\left[{ }^{124} \mathrm{I}\right] \mathrm{RmAb} 158-\mathrm{scFv} 8 \mathrm{D} 3 \mathrm{scans}(72 \mathrm{~h}$ after injection) expressed as standardized uptake value (SUV). (a): Comparison of representative SPECT and PET images of $\left[{ }^{125} \mathrm{I}\right] \mathrm{RmAb} 158-\mathrm{scFv} 8 \mathrm{D} 3$ and $\left[{ }^{11} \mathrm{C}\right] \mathrm{PiB}$ of $\mathrm{App}{ }^{\mathrm{NL}-\mathrm{G}-\mathrm{F}}$ and wild-type mice. (b, c): Retention of $\left[{ }^{125} \mathrm{I}\right] \mathrm{RmAb158-scFv8D} 3$ and $\left[{ }^{11} \mathrm{C}\right] \mathrm{PiB}$ in different brain regions of App ${ }^{\mathrm{NL}-\mathrm{G}-\mathrm{F}}$ and wildtype mice. Reproduced from [70] with permission from Society of Nuclear Medicine and Molecular Imaging; (d) Multi-modal analysis of the four AD mouse strains in cross-sectional $\left[{ }^{18} \mathrm{~F}\right]$ florbetaben PET study. Images indicate group averaged sagittal PET slices, normalised to the cerebellum as well as ex vivo autoradiography. Dots indicate PETSUVR cortex/cerebellum in individual mice. Dashed lines express the estimated time dependent progression in PS2APP (red); APPswe/PS1G384A (green); and APP/PS1 (purple) mice, fitted with a polynomial function. Reproduced from [61] with permission from PLOS One; (e-h) $\left[{ }^{18} \mathrm{~F}\right] \mathrm{GE}-180,\left[{ }^{18} \mathrm{~F}\right]$ florbetaben, and $\left[{ }^{18} \mathrm{~F}\right] \mathrm{FDG}$ PET imaging at different ages of PS2APP animals. (e) Coronal planes of mean SUVR maps projected on an MRI mouse atlas (gray scale). (f-h) Correlations between the different forebrain radiotracer SUVR for all PS2APP mice. Reproduced with permission [87] with permission from Society of Nuclear Medicine and Molecular Imaging.

Figure 2. In vivo imaging of synaptic density, blood-brain barrier and gama-secretase in amyloidosis animal models of Alzheimer's disease. (a-c) Representative $\left[{ }^{11} \mathrm{C}\right] \mathrm{UCB}-\mathrm{J}$ PET image and time-activity curve in APP/PS1 mice. (a) Static SUV image (30-60 min after injection) overlaid on atlas brain MR image. (b, c) Hippocampal SUVRs in wild-type and APP/PS1 mice during baseline, treatment, and washout phases: whole brain SUVR. (b) and brain stem SUVR (c). Reproduced from 
[104] with permission Society of Nuclear Medicine; (d-g) Imaging of P-glycoprotein (P-gp, ABCB1) using $(R)-\left[{ }^{11} \mathrm{C}\right]$ verapamil; (d) Sagittal PET summation images (0-60 min) of wild-type and APP/PS1 mice aged 50, 200 and 380 days and $A b c b 1 \mathrm{a} / \mathrm{b}^{(+/-)}$mice pre-treated i.v. with vehicle or tariquidar $(4 \mathrm{mg} / \mathrm{kg})$ at $2 \mathrm{~h}$ before start of the PET scan. (e-g) Whole brain region is highlighted as a white line (d, e). Whole brain-to-plasma radioactivity concentration ratios at the end of the PET scan (Kp,brain). Lines indicate mean \pm standard deviation. Ns: not significant, $* P<0.05, * * * P<0.001$. Reproduced from [161] from Sage Publication. (h-j) PET-CT imaging of $\gamma$-secretase in 5×FAD and wild-type mice. (h) PET-CT image of $5 \times$ FAD mice $(n=2)$ after i.v. injection of $\left[{ }^{11} \mathrm{C}\right] \mathrm{SGSM}-15606$. (i) PET-CT image of wild-type mice $(\mathrm{n}=2)$ after $i . v$. injection of $\left[{ }^{11} \mathrm{C}\right] \mathrm{SGSM}-15606$. (j) Time activity curve of whole brain uptake of $\left[{ }^{11} \mathrm{C}\right] \mathrm{SGSM}-15606$ in $\mathrm{h}$ and i. Data are expressed as the percentage of injected dose per cubic centimeter (\% ID/cc). Reproduced from [74] with permission from Rockefeller University Press.

Figure 3. In vivo imaging of astrocytosis, butyrylcholinesterase and triggering receptors expressed on myeloid cells (TREM) 2 in amyloidosis animal models of Alzheimer's disease. (a, b) $\left[{ }^{11} \mathrm{C}\right]$ deuterium-1-deprenyl ([ $\left.\left.{ }^{11} \mathrm{C}\right] \mathrm{DED}\right)$ microPET imaging in APPswe and wild-type (WT) mice. (a) $\left[{ }^{11} \mathrm{C}\right] \mathrm{DED}$ microPET coronal parametric $\mathrm{BP}_{\mathrm{ND}}$ maps images. (b) $\left[{ }^{11} \mathrm{C}\right] \mathrm{DED}$ binding in the cortex and hippocampus, expressed as $\mathrm{BP}_{\mathrm{ND}}$, obtained from simplified reference tissue model of $\left[{ }^{11} \mathrm{C}\right] \mathrm{DED}$ using the cerebellum as a reference region, in three groups of APPswe mice aged 6, 8-15 and 18-24 months and two groups of wild-type mice aged 8-15 and 18-24 months. Significant differences between groups are indicated by $* p<0.05$. Reproduced from [244] with permission from Springer Nature. (c-e) PET images for BChE imaging in 5×FAD mice. (c, d) axial view of PET images in $5 \times$ FAD and wild-type mice after i.v. administration of $\left[{ }^{11} \mathrm{C}\right] 4$ at different ages. (e) Staining for BChE enzymatic activity in 4, 8 and 12-month-old brains of wild-type (A, C and E) and 5×FAD mice (B, D and F) using the Karnovsky-Roots method. BChE staining showed increase of enzyme activity in the 
cerebral cortex of $5 \times \mathrm{FAD}$ at different ages in comparison to wild-type (A to F) mice. Magnified images show the co-occurence of plaques with BChE enzyme activity in different regions of the cerebral cortex (B, D and F) Reproduced from [153] with permission from Ivyspring International Publisher. (f-I) SPECT imaging of TREM2 level in ArcSwe, Swe and wild-type mice. (f) Representative SUV scaled sagittal SPECT images with [ $\left.{ }^{124} \mathrm{I}\right] \mathrm{mAb} 1729-\mathrm{scFv} 8 \mathrm{D} 3 \mathrm{CL}$ at $24 \mathrm{~h}, 48 \mathrm{~h}$, and $72 \mathrm{~h}$ after injection. (g) Radioligand distribution in brain tissue displayed in sagittal ex vivo autoradiography images in ArcSwe, Swe, and wild-type animals at $24 \mathrm{~h}$ and $72 \mathrm{~h}$ after injection (g). (h) Binding comparison of $\left[{ }^{125} \mathrm{I}\right] \mathrm{mAb} 1729-\mathrm{scFv} 8 \mathrm{D} 3 \mathrm{CL}$ and unlabelled mAb1729-scFv8D3CL by using ELISA. Percent of injected dose (i) and SUV (j) of [ $\left.{ }^{125} \mathrm{I}\right] \mathrm{mAb} 1729-\mathrm{scFv} 8 \mathrm{D} 3 \mathrm{CL}$ in brain $2 \mathrm{~h}, 24 \mathrm{~h}$, and $72 \mathrm{~h}$ after injection. (k) Level of $\left[{ }^{124} \mathrm{I}\right] \mathrm{mAb} 1729-\mathrm{scF} 8 \mathrm{D} 3 \mathrm{CL}$ in blood which was sampled $1 \mathrm{~h}, 3 \mathrm{~h}, 24 \mathrm{~h}, 48 \mathrm{~h}$, and $72 \mathrm{~h}$ after injection. (1) sTREM2 levels in TBS extracted brains of ArcSwe, APPSwe, and wild-type mice at the age of 18 months. Reproduced from [207] with permission from Springer Nature. 
Table 1. Amyloid-beta PET imaging in animal models of Alzheimer disease amyloidosis

\begin{tabular}{|c|c|c|}
\hline Tracer & Animal models & References \\
\hline \multirow{5}{*}[{}^{11}\mathrm{C}]{$\mathrm{PiB}$} & APPswe mice & {$[41,60,245]$} \\
\hline & $5 \times$ FAD mice & {$[85]$} \\
\hline & APP/PS1 mice & {$[40,60,82,86,246-248]$} \\
\hline & $3 \times \operatorname{Tg}$ mice & [249] \\
\hline & APP23 mice & {$[37,60,190]$} \\
\hline \multirow{7}{*}[{}^{18}\mathrm{F}]{ florbetapir, AV-45 } & Aged non-human primate & {$[89,145]$} \\
\hline & $5 \times$ FAD mice & {$[81,85]$} \\
\hline & TASTPM mice & {$[250]$} \\
\hline & APP/PS1 mice & {$[73,251]$} \\
\hline & PS2APP mice & {$[61,252]$} \\
\hline & APPswe mice & {$[61,253]$} \\
\hline & $\mathrm{App}^{\mathrm{NL}-\mathrm{G}-\mathrm{F}}$ mice & {$[68,192,197,252,254]$} \\
\hline \multirow{4}{*}[{}^{18}\mathrm{F}]{ florbetaben, $\mathrm{AV}-1$} & APPswe/PS1G384A mice & {$[61]$} \\
\hline & APP-SL70 mice & {$[252,255]$} \\
\hline & TgF334 rats & {$[152]$} \\
\hline & APP/PS1 mice & {$[61,68,82,256]$} \\
\hline \multirow[t]{2}{*}[{}^{11}\mathrm{C}]{$\mathrm{AZD} 2184$} & APPswe mice & [244] \\
\hline & APP/PS1 mice & [257] \\
\hline$\left[{ }^{18} \mathrm{~F}\right]$ flutafuranol AZD4694, & McGill-R-Thy1-APP rats & {$[47]$} \\
\hline NAV4694 & APPswe mice & {$[46]$} \\
\hline$\left[{ }^{18} \mathrm{~F}\right]$ flutemetamol & APP23, APPswe, APP/PS1 & {$[41,42]$} \\
\hline$\left[{ }^{18} \mathrm{~F}\right] \mathrm{FIBT}$ & APP/PS1 mice & {$[40]$} \\
\hline$\left[{ }^{18} \mathrm{~F}\right] \mathrm{FC} 119 \mathrm{~S}$ & $5 \times$ FAD, APP/PS1 mice & {$[38,39]$} \\
\hline$\left[{ }^{18} \mathrm{~F}\right] \mathrm{FACT},\left[{ }^{11} \mathrm{C}\right] \mathrm{BF}-227$ & APP/PS1 mice & {$[258,259]$} \\
\hline$\left[{ }^{18} \mathrm{~F}\right]$ fluselenamyl & APP/PS1 mice & {$[260]$} \\
\hline$\left[{ }^{125} \mathrm{I}\right] \mathrm{RmAb} 158$-scFv8D3 & Tg-ArcSwe, App ${ }^{\text {NL-G-F }}$ mice & {$[70]$} \\
\hline [25I]8D3-F(ab')2-h158 & Tg-ArcSwe, APPswe mice & {$[53]$} \\
\hline$\left[{ }^{18} \mathrm{~F}\right] \mathrm{CDA}-3$ & $5 \times$ FAD mice & {$[57]$} \\
\hline [125] IDRM106 & TgF344 rats, APPswe mice & {$[261,262]$} \\
\hline [ $\left.{ }^{125} 1\right] \mathrm{DRM} 106$ & $3 \times \mathrm{Tg}$ mice & {$[54]$} \\
\hline$\left[{ }^{64} \mathrm{Cu}\right] \mathrm{HYR}-17$ & $5 \times$ FAD mice & {$[43]$} \\
\hline$\left[{ }^{64} \mathrm{Cu}\right] 8 \mathrm{a}^{\prime}-8 \mathrm{~d}$ & $5 \times$ FAD mice & [48] \\
\hline$\left[{ }^{18} \mathrm{~F}\right] \mathrm{DRKXH} 1$ & APP/PS1 mice & [44] \\
\hline [ ${ }^{125}$ I]DRK092 & APPswe mice & [55] \\
\hline$\left[{ }^{125} \mathrm{I}\right] \mathrm{CQ}-\mathrm{PBCA}$ NPs & APP/PS1 mice & [56] \\
\hline$\left[{ }^{18} \mathrm{~F}\right] \mathrm{CABS} 13$ & APP/PS1 mice & {$[45]$} \\
\hline Resorufin; $\left[{ }^{3} \mathrm{H}\right] 1,2$ & Tg-ArcSwe mice & [66] \\
\hline $\begin{array}{c}{\left[{ }^{99 \mathrm{~m}} \mathrm{Tc}\right] \text { hydroxamamide }} \\
\text { complexes }\end{array}$ & APPswe mice & [67] \\
\hline
\end{tabular}


Table 2. PET imaging in of neurotransmitter receptors, blood-brain barriers, enzymes, metabolism and synaptic density in animal models of Alzheimer disease amyloidosis

\begin{tabular}{|c|c|c|c|}
\hline Target & Tracer & Animal models & References \\
\hline \multirow{10}{*}{ CMRglc } & \multirow{10}{*}[{}^{18}\mathrm{F}]{$\mathrm{FDG}$} & $3 \times \mathrm{Tg}$ mice & {$[83,263-267]$,} \\
\hline & & APPswe mice & [79] \\
\hline & & APP/PS1 mice & {$[73,82,88,250,268-270]$} \\
\hline & & Tg4-42 mice & {$[78,271]$} \\
\hline & & $5 \times$ FAD mice & {$[81,85,256,272,273]$} \\
\hline & & $3 \times \mathrm{Tg}$ rats & {$[274]$} \\
\hline & & APP23 mice & [275] \\
\hline & & $\begin{array}{c}\text { McGill-R-Thy1- } \\
\text { APP rats }\end{array}$ & [47] \\
\hline & & TASTPM mice & {$[250,276]$} \\
\hline & & Aged monkey & [89] \\
\hline \multirow{4}{*}{ SV2A } & \multirow{3}{*}[{}^{11}\mathrm{C}]{$\mathrm{UCB}-\mathrm{J}$} & $\begin{array}{l}\text { Striatal-lesioned } \\
\text { rats }\end{array}$ & {$[14,103,104]$} \\
\hline & & APP/PS1 mice & [104] \\
\hline & & $\begin{array}{l}\text { ArcSwe, Tg-L61 } \\
\text { mice }\end{array}$ & {$[105]$} \\
\hline & {$\left[{ }^{18} \mathrm{~F}\right]$ SynVesT-1 } & APP/PS1 mice & [107] \\
\hline \multirow{3}{*}{ mGluR5 } & $\left.{ }^{18} \mathrm{~F}\right] \mathrm{FPFB}$ & $5 \times$ FAD mice & {$[131,277]$} \\
\hline & {$\left[{ }^{10} \mathrm{~F}\right] \mathrm{FPEB}$} & APP/PS1 mice & [132] \\
\hline & {$\left[{ }^{11} \mathrm{C}\right] \mathrm{ABP} 688$} & Tg-ArcSwe mice & [133] \\
\hline \multirow{2}{*}{$\alpha 7 \mathrm{nAChR}$} & {$\left[{ }^{11} \mathrm{C}\right] \mathrm{MeQAA}$} & Aged monkey & [145] \\
\hline & {$\left[{ }^{18} \mathrm{~F}\right] \mathrm{ASEM}$} & TgF334 rats & [152] \\
\hline $\mathrm{AChE}$ & {$\left[{ }^{11} \mathrm{C}\right] \mathrm{MP} 4 \mathrm{~A}$} & APP23 mice & [154] \\
\hline $\mathrm{BChE}$ & {$\left[{ }^{11} \mathrm{C}\right] 4$} & $5 \times$ FAD mice & [153] \\
\hline GABAR & {$\left[{ }^{11} \mathrm{C}\right]$ flumazenil } & APP23 mice & {$[154]$} \\
\hline GSM & {$\left[{ }^{11} \mathrm{C}\right] \mathrm{SGSM}-1560$} & $5 \times$ FAD mice & {$[74]$} \\
\hline IIa HDAC & {$\left[{ }^{18} \mathrm{~F}\right] \mathrm{TFAHA}$} & $3 \times \mathrm{Tg}$ mice & [278] \\
\hline GLP-1R & {$\left[{ }^{18} \mathrm{~F}\right]$ FBEM-Cys ${ }^{39}$-exendin-4 } & $3 \times \mathrm{Tg}$ mice & [267] \\
\hline $\mathrm{D}_{2} \mathrm{R}$ & {$\left[{ }^{18} \mathrm{~F}\right]$ fallypride } & $\begin{array}{c}3 \times \mathrm{Tg}, 5 \times \mathrm{FAD} \\
\text { mice }\end{array}$ & {$[267,277]$} \\
\hline $\mathrm{MC} 1$ & {$\left[{ }^{18} \mathrm{~F}\right] \mathrm{BCPP}-\mathrm{EF}$} & $\begin{array}{l}\text { Aged monkey } \\
\text { SAMP10 mice }\end{array}$ & {$[89,145,217,279]$} \\
\hline Copper & {$\left[{ }^{64} \mathrm{Cu}\right] \mathrm{GTSM}$} & TASTPM mice & [208] \\
\hline MT & {$\left[{ }^{11} \mathrm{C}\right] \mathrm{MPC}-6827$} & $\mathrm{~J} 20$ mice & {$[213]$} \\
\hline \multirow{2}{*}{ GSK3 $\beta$} & {$\left[{ }^{11} \mathrm{C}\right] \mathrm{OCM}-44,\left[{ }^{3} \mathrm{H}\right] \mathrm{PF}-367$} & APPswe mice & {$[280]$} \\
\hline & {$\left[{ }^{11} \mathrm{C}\right] 2$} & $3 \times \operatorname{Tg}$ mice & {$[218]$} \\
\hline \multirow{4}{*}{ RAGE } & {$\left[{ }^{18} \mathrm{~F}\right] \mathrm{RAGER}$} & Rats & {$[172]$} \\
\hline & {$\left[{ }^{18} \mathrm{~F}\right] \operatorname{InRAGER}$} & LPS-treated mice & {$[173]$} \\
\hline & {$\left[{ }^{11} \mathrm{C}\right] \mathrm{FPS}-\mathrm{ZM} 1$} & APPswe mice & {$[175]$} \\
\hline & {$\left[{ }^{64} \mathrm{Cu}\right]$ Rho-G4-CML NP } & $\begin{array}{l}\text { Murine model of } \\
\text { hindlimb } \\
\text { ischemia }\end{array}$ & {$[174]$} \\
\hline $\mathrm{ABCC} 1$ & {$\left[{ }^{11} \mathrm{C}\right] \mathrm{BMP}$} & APP/PS1 mice & {$[165]$} \\
\hline \multirow[t]{2}{*}{$\mathrm{ABCG} 2$} & {$\left[{ }^{11} \mathrm{C}\right]$ erlotinib } & APP/PS1 mice & {$[166]$} \\
\hline & {$\left[{ }^{11} \mathrm{C}\right]$ tariquidar } & APP/PS1 mice & [166] \\
\hline
\end{tabular}


$\left[{ }^{11} \mathrm{C}\right]$ metoclopramide $\quad$ APP/PS1 mice

[162]

(R)-O-

$\left[{ }^{18} \mathrm{~F}\right]$ fluoroethylnorverapamil,

P-GP

(R)-N-

$\operatorname{Mdrla} / b^{(-/-)}$,

$\left.\operatorname{Bcrpl}_{\text {rats }}^{(-/-}\right)$mice,

ABCB1 $\quad\left[{ }^{18} \mathrm{~F}\right]$ fluoroethylverapamil

[164]

$\left[{ }^{18} \mathrm{~F}\right] \mathrm{MC} 225$

Non-human

primates, rats

(R)-[ $\left[{ }^{11} \mathrm{C}\right]$ verapamil

APP/PS1 mice

$[167,168]$

[161]

ABC: ATP-binding cassette transporter; $\alpha 7$ nAChR: $\alpha 7$ icotinic acetylcholine receptor; AChE, acetylcholine esterase; BChE: butyrylcholinesterase; CMRglc: cerebral metabolic rate of glucose; D2: dopamine receptor D2; FDG: fluorodeoxyglucose; GABAR: gamma-Aminobutyric acid receptor; GLP-1R: glucagon-like peptide-1 receptor; GSK3 $\beta$ : glycogen synthase kinase-3b; GSM: $\gamma$ secretase modulator; IIa HDAC: class IIa histone deacetylases; LPS: Lipopolysaccharide; MC1: mitochondrial complex 1; mGluR5: metabotropic glutamate receptor type 5; MT: microtubule; NP: nanoparticle; P-GP: P-Glycoprotein; SV2A: synaptic vesicle glycoprotein 2A; 
Fig. 1
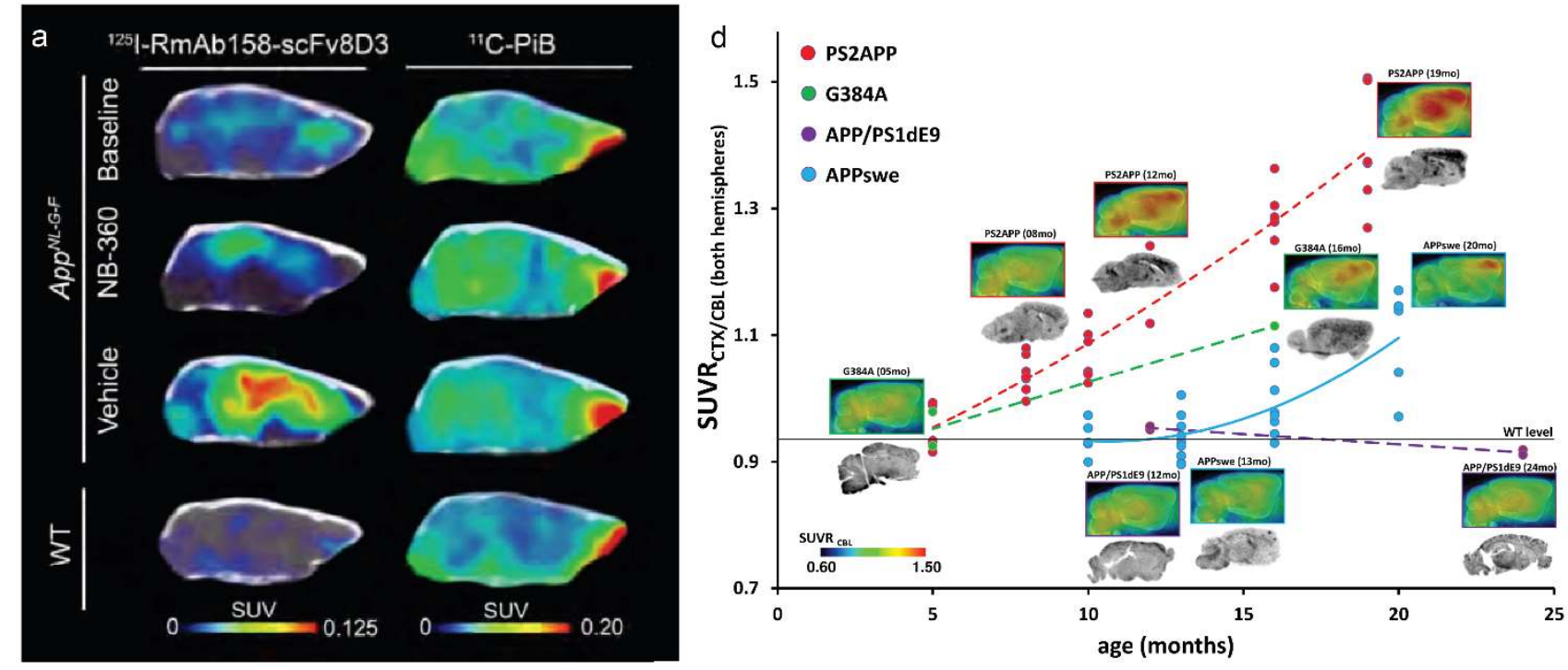

b
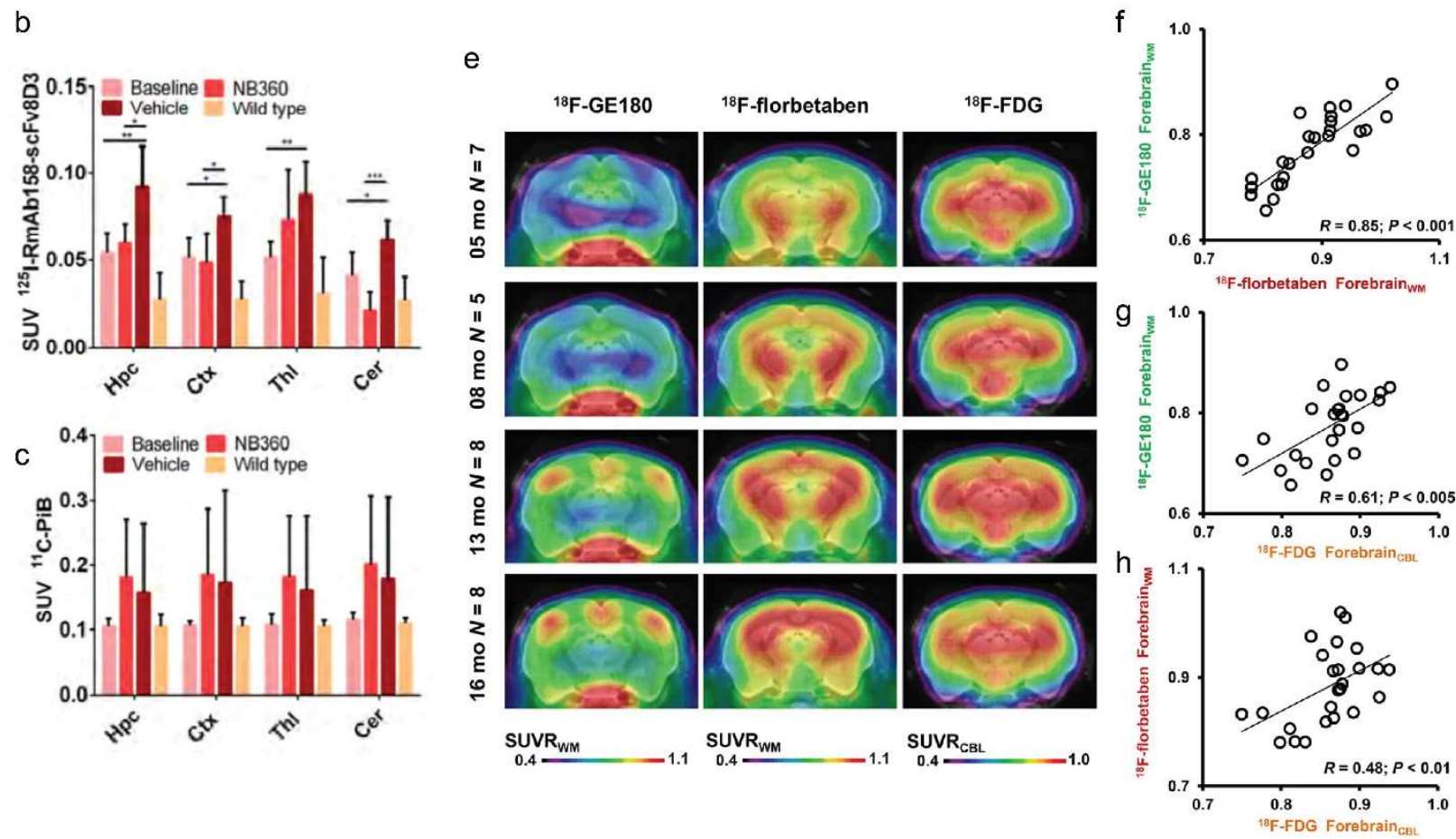
Fig. 2

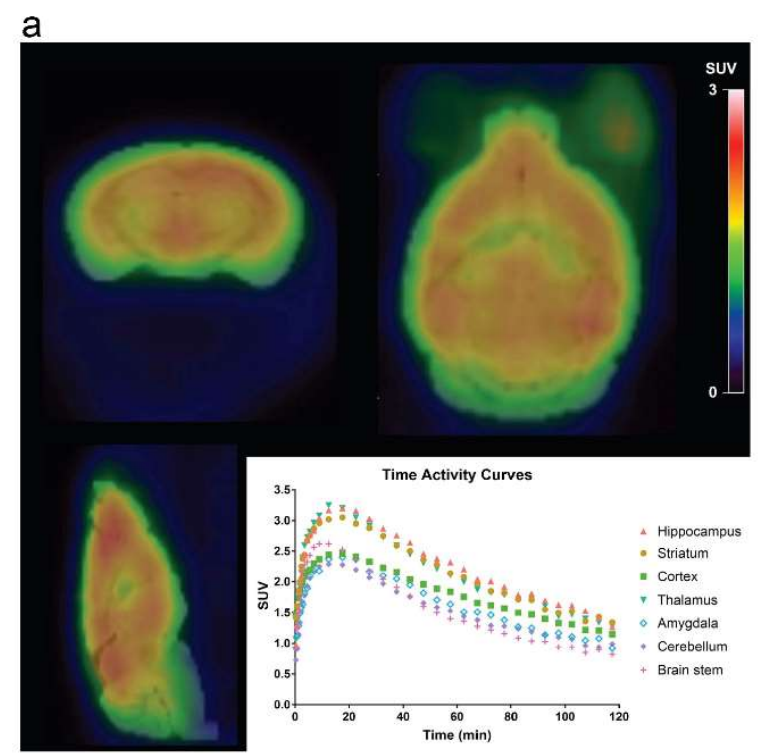

d
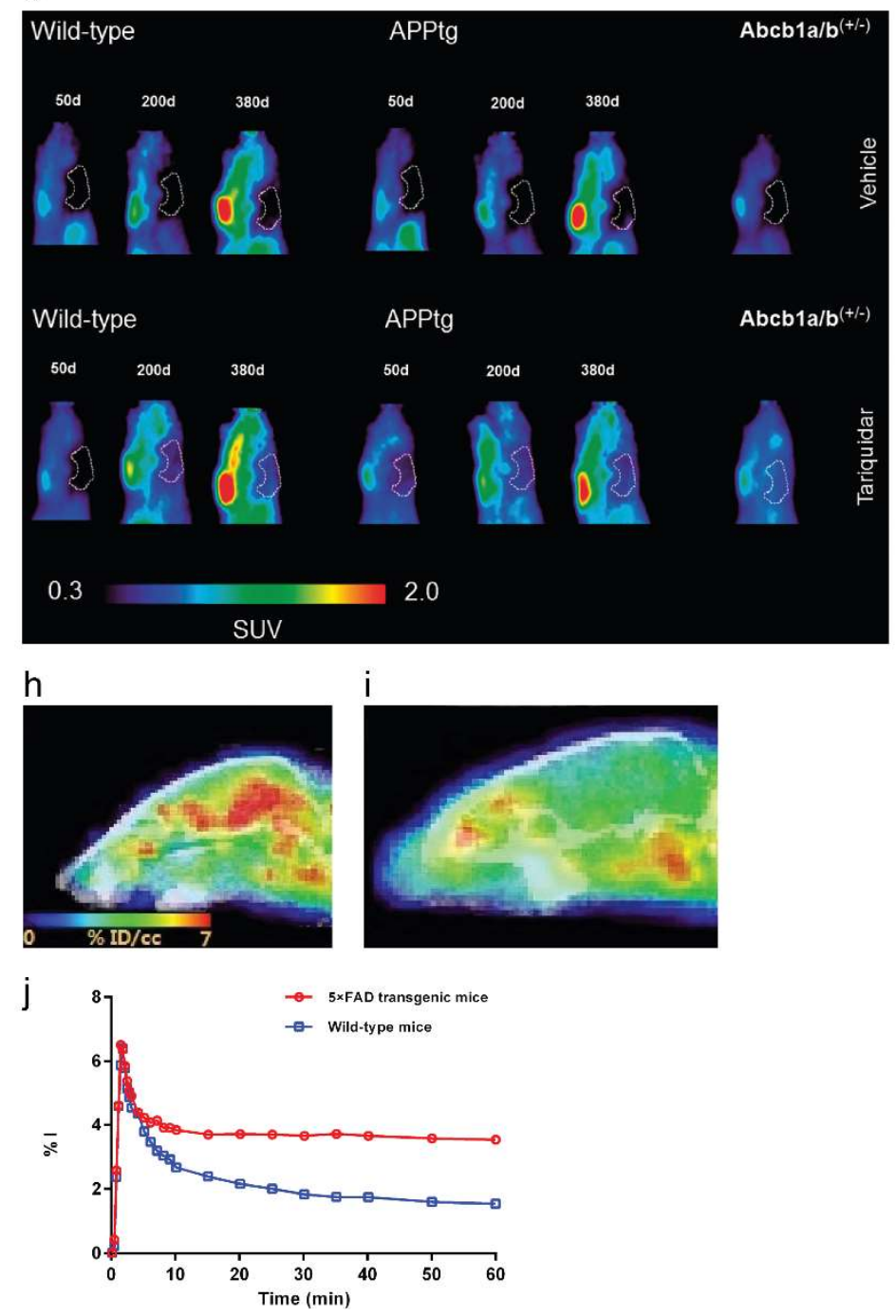
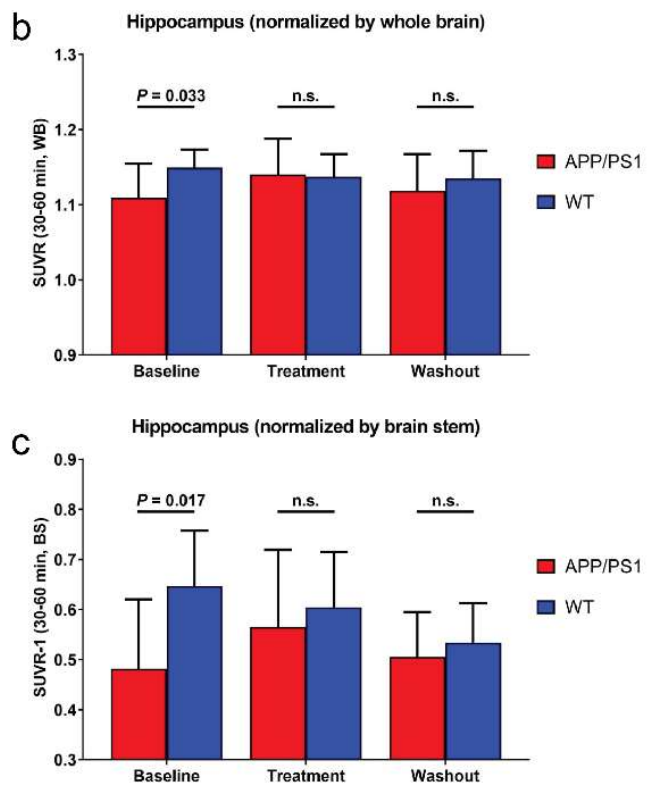
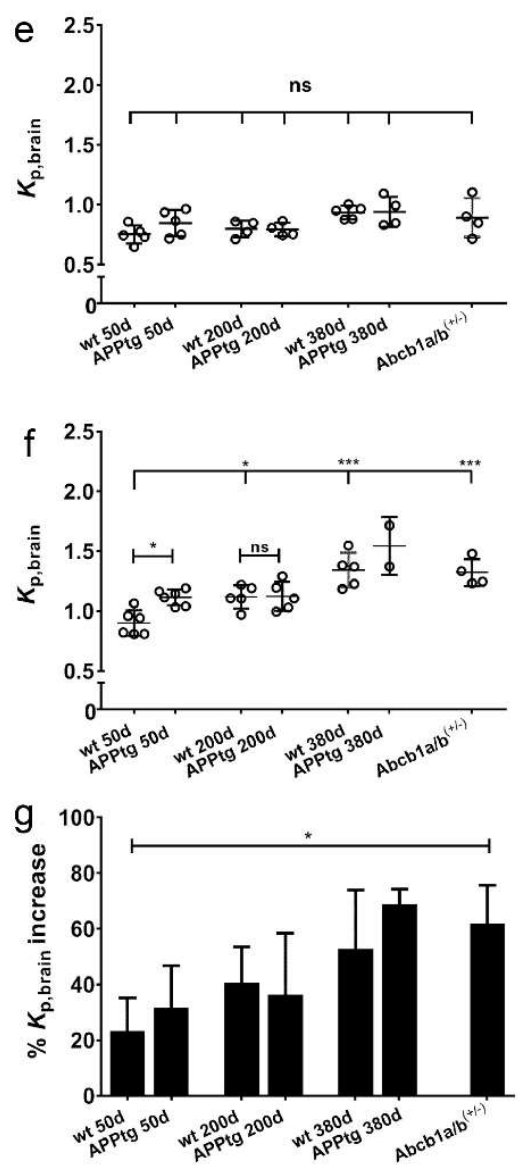
Fig. 3
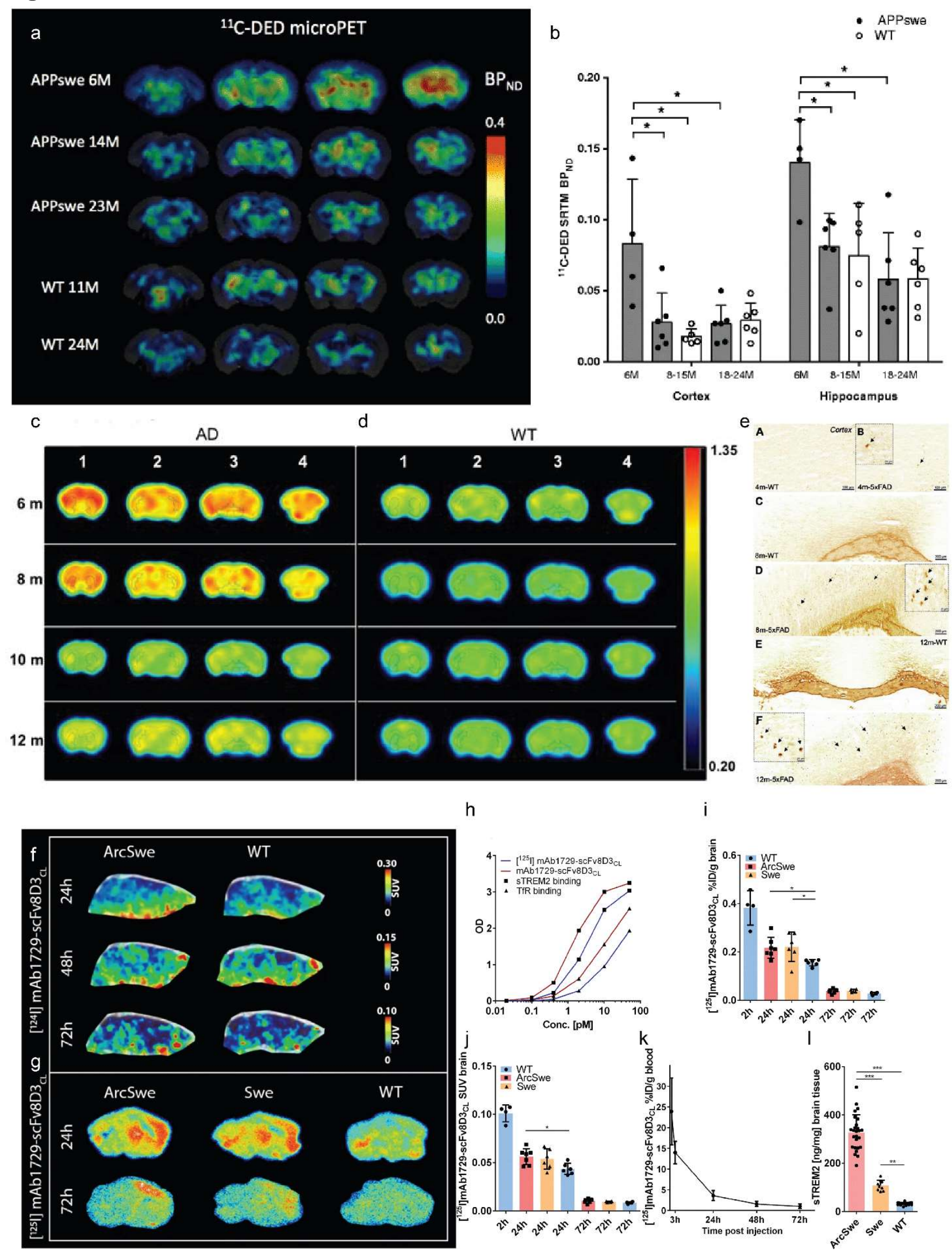